Check for updates

Cite this: RSC Adv., 2018, 8, 4014

\title{
$\mathrm{V}_{2} \mathrm{O}_{5}$-Based nanomaterials: synthesis and their applications
}

\author{
Xuyan Liu, (D) a Jiahuan Zeng, ${ }^{a}$ Huinan Yang, ${ }^{b}$ Kai Zhou ${ }^{a}$ and Deng Pan*a
}

As an important part of lithium-ion batteries, the cathode material can directly affect the performance of lithium-ion batteries. However, with the increasing demand for high-energy and high-power devices, the energy and power density of electrode materials need to be further improved. Among all metal oxides, vanadium pentoxide $\left(\mathrm{V}_{2} \mathrm{O}_{5}\right)$ is regarded as a promising candidate to serve as a cathode material for LIBs due to its high theoretical capacity. Herein, a thorough survey of the synthesis of $\mathrm{V}_{2} \mathrm{O}_{5}$-based nanomaterials with various structures and chemical compositions and their application as positive electrodes for LIBs is provided. This review covers $\mathrm{V}_{2} \mathrm{O}_{5}$ with different morphologies ranging from 1D nanorods/nanowires/nanotubes/nanofibers/nanobelts, to 2D nanosheets, and to 3D hollow and porous nanostructures. Nanocomposites consisting of $\mathrm{V}_{2} \mathrm{O}_{5}$ and different carbonaceous supports, e.g., amorphous carbon, carbon nanotubes, and graphene, are also investigated. The cation-doped $\mathrm{V}_{2} \mathrm{O}_{5}$ samples as the cathode material for LIBs are briefly discussed as well. The aim of this review is to provide an in-depth and rational understanding of how the electrochemical properties of $\mathrm{V}_{2} \mathrm{O}_{5}$-based cathodes can be effectively enhanced by achieving proper nanostructures with optimized chemical composition.

Received 17th November 2017 Accepted 7th January 2018

DOI: 10.1039/c7ra12523b

rsc.li/rsc-advances phones, laptops and digital electronics. ${ }^{\mathbf{1 0 - 1 2}}$ Current LIB technology is well developed for portable electronic devices and has been widely used for the past twenty years. However, the employment of Li-ion batteries in hybrid electric vehicles (HEV), plug-in hybrid electric vehicles (PHEV) and pure electric vehicles (PEV) needs two to five times more energy density than the existing lithium batteries can offer $\left(150 \mathrm{~W} \mathrm{~h} \mathrm{~kg}^{-1}\right) .{ }^{13}$ Therefore, further LIB material and system developments are necessary.

Fig. 1 shows a typical lithium-ion battery. ${ }^{25}$ Obviously, there are four key components in an LIB system: cathode, anode, separator and electrolyte. ${ }^{14}$ The electrolyte allows lithium ions to travel between the electrodes, and a separator keeps the

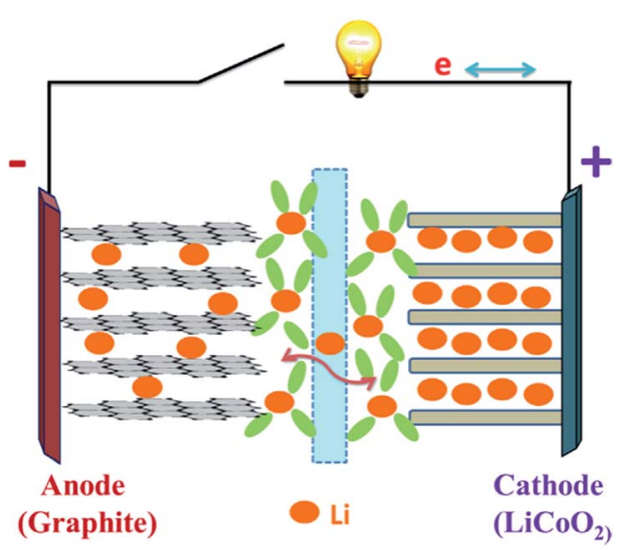

Fig. 1 Schematic of a lithium-ion battery during the charge/discharge process. ${ }^{25}$ 
anode and the cathode from making direct contact. ${ }^{18-21}$ Firstgeneration LIBs employ the graphite as the anode, layered $\mathrm{LiCoO}_{2}$ as the cathode, and the organic liquid $\mathrm{LiPF}_{6} /$ ethylene carbonate (EC)/dimethylene carbonate (DMC) as the electrolyte. ${ }^{15-17}$ The LIB performance (e.g., cell potential, capacity and energy density) is largely dependent on the intrinsic chemistry of the negative and positive electrode materials. The cathode usually consists of a metal oxide, and the anode tends to be a carbon material. At present, cathode materials for commercial LIBs are mainly transition metals oxides or active phosphates, such as $\mathrm{LiCoO}_{2},{ }^{26,27} \mathrm{LiNiO}_{2},{ }^{28,29} \mathrm{LiMn}_{2} \mathrm{O}_{4},{ }^{30,31}$ and $\mathrm{LiFePO}_{4} \cdot^{32,33}$ Comparison of several kinds of cathode materials for lithium ion batteries is listed in Table 1, while graphite is commonly used as the anode active material. Lithium-ion batteries charge and discharge through a process of lithiation (lithium insertion) and de-lithiation (lithium extraction) by means of electrochemical reactions. In this process, lithium ions diffuse back and forth through the electrolyte between the anode and the cathode. During lithiation (discharging), the lithium bonded with the anode material breaks apart, producing lithium ions and electrons, and these lithium ions travel and bond with metal oxides on the cathode side and the electrons produce the electrical energy that powers devices. During de-lithiation (charging), the lithium metal oxides from the cathode break apart, producing lithium ions that pass through the electrolyte and bond with the material on the anode side with the addition of electrons. ${ }^{22-24}$

In the past decade, because of the significant advances in nanotechnology and materials science, numerous nanostructured materials have been applied as electrode materials for LIBs. Among the potential cathode materials, layered vanadium pentoxide $\left(\mathrm{V}_{2} \mathrm{O}_{5}\right)$ is one of the most attractive cathode materials and has been extensively studied because of its low cost, abundance, ease of synthesis, good safety and relatively high theoretical capacity of $\sim 437 \mathrm{~mA} \mathrm{~h} \mathrm{~g}^{-1}$, which is much higher than that of the currently used $\mathrm{LiCoO}_{2}$-based anodes $\left(\sim 274 \mathrm{~mA} \mathrm{~h} \mathrm{~g}{ }^{-1}\right) \cdot{ }^{34,35} \mathrm{In}$ a $\mathrm{Li} / \mathrm{V}_{2} \mathrm{O}_{5}$ half-cell, the $\mathrm{Li}^{+}$intercalation and de-intercalation process can be expressed by the following equation: ${ }^{36}$

$$
\mathrm{V}_{2} \mathrm{O}_{5}+x \mathrm{Li}^{+}+x \mathrm{e}^{-} \rightarrow \mathrm{Li}_{x} \mathrm{~V}_{2} \mathrm{O}_{5}
$$

As $\mathrm{Li}^{+}$are inserted into the layers of $\mathrm{V}_{2} \mathrm{O}_{5}$, phase transformation occurs. Theoretically, the process of $\mathrm{Li}^{+}$intercalation into $\mathrm{V}_{2} \mathrm{O}_{5}$ can be divided into several stages and different phases of $\mathrm{Li}_{x} \mathrm{~V}_{2} \mathrm{O}_{5}$ can be formed in each stage. Fig. 2 shows the electrochemical lithium intercalation into $\mathrm{V}_{2} \mathrm{O}_{5}$, showing the evolution of phases with the degree of lithium intercalation. ${ }^{\mathbf{4 0}}$ The structural behaviour of vanadium oxide with increased $\mathrm{Li}$ insertion is quite complex and it can split into several different phases. According to the amount of lithium, $x$, there are five phases, $\alpha-\mathrm{V}_{2} \mathrm{O}_{5}(x<0.01), \varepsilon-\mathrm{Li}_{x} \mathrm{~V}_{2} \mathrm{O}_{5}(0.35<x<0.7), \delta-\mathrm{Li}_{x} \mathrm{~V}_{2} \mathrm{O}_{5}(x$ $=1), \gamma-\mathrm{Li}_{x} \mathrm{~V}_{2} \mathrm{O}_{5}(x<2)$ and $\omega-\mathrm{Li}_{x} \mathrm{~V}_{2} \mathrm{O}_{5}(x>2) \cdot{ }^{37,38}$ The phases of the lithiated vanadium oxide $\mathrm{Li}_{x} \mathrm{~V}_{2} \mathrm{O}_{5}$ and the corresponding electrochemical reactions are listed in Table 2. Among these phases of $\mathrm{Li}_{x} \mathrm{~V}_{2} \mathrm{O}_{5}$, the first phase $\alpha-\mathrm{V}_{2} \mathrm{O}_{5}$ has little effect on the $\mathrm{V}_{2} \mathrm{O}_{5}$ structure. This phase is followed by the $\varepsilon$-phase in which the vanadium oxide layers become more puckered. The $\delta$-phase occurs when $x=1$, and as can be seen from Fig. 2, at this phase, there is a sudden decrease in cell potential. Due to the intercalation of $\mathrm{Li}^{+}$, slight structural modifications occur, such as puckering of the layers and increasing of interlayer spacing; however, the basic layered structure is maintained. If more than one $\mathrm{Li}^{+}$are intercalated, the $\delta$-phase is transformed into the $\gamma$ $\mathrm{Li}_{x} \mathrm{~V}_{2} \mathrm{O}_{5}$ phase via an irreversible reconstruction mechanism. The $\gamma-\mathrm{Li}_{x} \mathrm{~V}_{2} \mathrm{O}_{5}$ phase can itself be reversibly cycled in the range of $0<x<2$ while maintaining the $\gamma$-type structure. When even more $\mathrm{Li}^{+}$are intercalated, a rock salt structure of $\omega-\mathrm{Li}_{x} \mathrm{~V}_{2} \mathrm{O}_{5}$ is irreversibly formed. It has been reported that discharging $\mathrm{V}_{2} \mathrm{O}_{5}$ to the $\omega-\mathrm{Li}_{x} \mathrm{~V}_{2} \mathrm{O}_{5}$ phase would result in a rapid capacity loss with increased cycling, which is not desirable for the cathode material. Although the theoretical capacity of $\mathrm{V}_{2} \mathrm{O}_{5}$ is pretty high, the practical capacity of unmodified $\mathrm{V}_{2} \mathrm{O}_{5}$ is far from

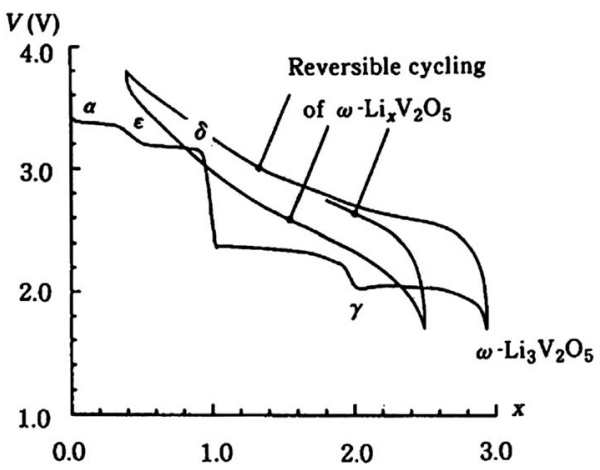

Fig. 2 Various phases associated with the electrochemical intercalation of lithium into $\mathrm{V}_{2} \mathrm{O}_{5}{ }^{40}$

Table 1 Comparison of several kinds of cathode materials for lithium-ion batteries

\begin{tabular}{|c|c|c|c|c|}
\hline Material category & $\mathrm{LiCoO}_{2}$ & $\mathrm{LiNiO}_{2}$ & $\mathrm{LiMn}_{2} \mathrm{O}_{4}$ & $\mathrm{LiFePO}_{4}$ \\
\hline Operating voltage/V & $2.5-4.2$ & $2.5-4.2$ & $3-4$ & About 3.4 \\
\hline Theoretical capacity/mA h g ${ }^{-1}$ & 274 & 275 & 148 & 170 \\
\hline Electrical conductivity/S $\mathrm{cm}^{-1}$ & $10^{-3}$ & $10^{-1}$ & $10^{-5}$ & $10^{-9}$ \\
\hline Safety & Poor & Poor & Good & Good \\
\hline Cycle life & $>500$ & Poor & $>500$ & $>500$ \\
\hline
\end{tabular}

performance 
Table 2 Phases of the lithiated vanadium oxide $\mathrm{Li}_{x} \mathrm{~V}_{2} \mathrm{O}_{5}$ and the corresponding electrochemical reactions

\begin{tabular}{lll}
\hline Value of $x$ in $\mathrm{Li}_{x} \mathrm{~V}_{2} \mathrm{O}_{5}$ & Phase & Electrochemical reactions \\
\hline$x<0.01$ & $\alpha-\mathrm{V}_{2} \mathrm{O}_{5}$ & $\mathrm{~V}_{2} \mathrm{O}_{5}+x \mathrm{Li}^{+}+x \mathrm{e}^{-} \rightarrow \alpha-\mathrm{Li}_{x} \mathrm{~V}_{2} \mathrm{O}_{5}$ \\
$0.35<x<0.7$ & $\varepsilon-\mathrm{Li}_{x} \mathrm{~V}_{2} \mathrm{O}_{5}$ & $\mathrm{~V}_{2} \mathrm{O}_{5}+x \mathrm{Li}^{+}+x \mathrm{e}^{-} \rightarrow \varepsilon-\mathrm{Li}_{x} \mathrm{~V}_{2} \mathrm{O}_{5}$ \\
$x=1$ & $\delta-\mathrm{Li}_{x} \mathrm{~V}_{2} \mathrm{O}_{5}$ & $\mathrm{~V}_{2} \mathrm{O}_{5}+x \mathrm{Li}^{+}+x \mathrm{e}^{-} \rightarrow \delta-\mathrm{Li}_{x} \mathrm{~V}_{2} \mathrm{O}_{5}$ \\
$x<2$ & $\gamma-\mathrm{Li}_{x} \mathrm{~V}_{2} \mathrm{O}_{5}$ & $\mathrm{~V}_{2} \mathrm{O}_{5}+x \mathrm{Li}^{+}+x \mathrm{e}^{-} \rightarrow \gamma-\mathrm{Li}_{x} \mathrm{~V}_{2} \mathrm{O}_{5}$ \\
$x>2$ & $\omega-\mathrm{Li}_{x} \mathrm{~V}_{2} \mathrm{O}_{5}$ & $\mathrm{~V}_{2} \mathrm{O}_{5}+x \mathrm{Li}^{+}+x \mathrm{e}^{-} \rightarrow \omega-\mathrm{Li}_{x} \mathrm{~V}_{2} \mathrm{O}_{5}$
\end{tabular}

satisfactory because of low electrical conduction, slow $\mathrm{Li}^{+}$ diffusion and irreversible phase transitions upon deep discharge. ${ }^{39}$ This would induce a huge influence in the electrode material, which leads to disintegration and loss of electric contact and eventually results in quick capacity fading upon prolonged cycling.

In this review, we propose a systematic description of $\mathrm{V}_{2} \mathrm{O}_{5^{-}}$ based nanomaterials ranging from synthesis, to modification, structure and electrochemical application. In the first section, we will provide an overview of the formation of $\mathrm{V}_{2} \mathrm{O}_{5}$ materials through dimensional structure design. It includes the survey of phase-pure $\mathrm{V}_{2} \mathrm{O}_{5}$ with unique $1 \mathrm{D}, 2 \mathrm{D}$, and $3 \mathrm{D}$ nanostructures. Then, we will illustrate the development of carbonaceous materials into $\mathrm{V}_{2} \mathrm{O}_{5}$ electrodes for LIBs. In the last section, cation-doped $\mathrm{V}_{2} \mathrm{O}_{5}$ samples as the cathode material for LIBs will be briefly discussed. We thus believe that this review article could serve as a good reference for $\mathrm{V}_{2} \mathrm{O}_{5}$-based nanomaterials.

\section{Phase-pure $\mathrm{V}_{2} \mathrm{O}_{5}$}

As a cathode material for LIBs, vanadium-based oxides have attracted worldwide attention because of their high capacity, low cost and abundance. ${ }^{41,42}$ Moreover, $\mathrm{V}_{2} \mathrm{O}_{5}$ has also been widely used in photocatalysts, ${ }^{43}$ sensors ${ }^{4,45}$ and electrochromic devices. ${ }^{46}$ To synthesize nanostructured $\mathrm{V}_{2} \mathrm{O}_{5}$, a variety of methods, including sol-gel processing, template-based methods, thermal evaporation, hydrothermal/solvothermal synthesis, reverse micelle techniques, and electrochemical deposition, have been developed. Among these methods, hydrothermal synthesis is considered the easiest and most effective way. With the assistance of surfactants, different morphologies of $\mathrm{V}_{2} \mathrm{O}_{5}$ are prepared by the hydrothermal method..$^{4-50}$ Table 3 summarizes the electrochemical properties of vanadium pentoxide as a cathode material for various $1 \mathrm{D}, 2 \mathrm{D}$ and 3D nanostructures.

\subsection{D nanostructures}

Among the many vanadium oxide nanomaterials, onedimensional nanostructured vanadium oxide is the most studied because its preparation method is relatively simple, it has a large specific surface area compared with traditional cathode materials, and it shows good cycling stability and high specific capacity. Among the various types of nanostructures, 1D $\mathrm{V}_{2} \mathrm{O}_{5}$ nanostructures with nanoscale radial dimensions, including nanorods, ${ }^{53-60}$ nanowires, ${ }^{65-69}$ nanotubes, ${ }^{72-76}$ nanofibers ${ }^{77-80}$ and nanobelts, ${ }^{81-84}$ have exhibited distinct advantages in LIBs. ${ }^{51,52}$

2.1.1 $\mathbf{V}_{2} \mathbf{O}_{5}$ nanorods. In 2008 , Glushenkov's group ${ }^{53}$ reported a novel solid-state process capable of producing large quantities of belt-like $\mathrm{V}_{2} \mathrm{O}_{5}$ nanorods. In this approach, $\mathrm{V}_{2} \mathrm{O}_{5}$ powder was mechanically milled in a ball mill first to produce a nanocrystalline precursor and then annealed in air. Nanorods were formed via a controlled recrystallization process during annealing. The growth process, morphology and structure of the nanorods were presented. The authors discovered that the annealing time was advantageous for the nanorod formation. Starting from the second cycle, the nanorods maintained a stable capacity of around $260 \mathrm{~mA} \mathrm{~h} \mathrm{~g}{ }^{-1}$ with no sign of significant degradation. The $\mathrm{V}_{2} \mathrm{O}_{5}$ nanorods in our study demonstrated a good cycling stability, which could be correlated to their small size and beneficial crystal orientation. Zhu et al. discovered an electrospinning method to produce $\mathrm{V}_{2} \mathrm{O}_{5}$ nanorods (Fig. 3). The method added $\mathrm{H}_{2} \mathrm{C}_{2} \mathrm{O}_{4}$ to increase the solubility of cheap $\mathrm{NH}_{4} \mathrm{VO}_{3}$ in water at room temperature and took mixed solvent of deionized water and $N, N$-dimethylformamide (DMF) to make the spinning process easier. In the end, $\mathrm{V}_{2} \mathrm{O}_{5}$ micro/nanorods were successfully prepared. Further, the $\mathrm{V}_{2} \mathrm{O}_{5}$ micro/nanorod cathodes showed a high lithium storage performance with the first discharge capacity of $418.8 \mathrm{~mA} \mathrm{~h} \mathrm{~g}{ }^{-1}$ and the 50th discharge capacity of $180.5 \mathrm{~mA} \mathrm{~h} \mathrm{~g}^{-1}$ when the half-cell was cycled between 2.0 and $4.0 \mathrm{~V}$ at a current density of $50 \mathrm{~mA} \mathrm{~g}^{-1}$.

Subsequently, Glushenkov et al. ${ }^{56}$ prepared nanorods of $\mathrm{V}_{2} \mathrm{O}_{5}$ via a two-stage procedure of ball milling and annealing in air. Commercially purchased $\mathrm{V}_{2} \mathrm{O}_{5}$ powder was milled in a ball mill as the first step of the synthesis. The as-milled precursor was subsequently annealed in air to produce nanorods via solidstate recrystallization. Takahashi et al. ${ }^{57}$ synthesized singlecrystal $\mathrm{V}_{2} \mathrm{O}_{5}$ nanorod arrays using template-based electrodeposition and the electrochemical results demonstrated that the nanorod array electrodes had significantly higher current density and energy storage density than sol-gel-derived $\mathrm{V}_{2} \mathrm{O}_{5}$ films. Uniformly sized vanadium oxide nanorods with a length of about $10 \mu \mathrm{m}$ and with diameters ranging from 100 to $200 \mathrm{~nm}$ were grown over a large area with near unidirectional alignment. This electrode exhibited high rate discharge capacity and good cycling stability.

2.1.2 $\mathrm{V}_{2} \mathrm{O}_{5}$ nanowires. Since oxide nanorods were first produced by Yang and Lieber in 1996, oxide nanorods and nanowires have received great interest. ${ }^{61}$ Recently, oxide nanowire electrodes have been found to exhibit excellent cycling performance because of their high surface area, short Li-ion diffusion distance, and facile strain relaxation on electrochemical cycling. ${ }^{62-64}$ Particularly, among all nanomaterials, nanowires not only reduce the volume strain, but also provide effective channels for the transmission of electrons along the length. Mai et al. ${ }^{65}$ prepared ultralong hierarchical vanadium oxide nanowires by electrospinning combined with annealing. They used cheap ammonium metavanadate as the raw material; after the addition of polyvinyl alcohol (PVA) in water and ammonium metavanadate, a precursor aqueous solution was prepared. Then the $\mathrm{NH}_{4} \mathrm{VO}_{3} / \mathrm{PVA}$ composite nanowires were 
Table 3 Electrochemical performance of one-dimensional nanostructured vanadium pentoxide for Li-ion battery cathode materials

\begin{tabular}{|c|c|c|c|c|c|}
\hline Precursor material & Nanostructures & $\begin{array}{l}\text { Initial capacity/ } \\
\mathrm{mA} \mathrm{h} \\
\mathrm{g}^{-1}\end{array}$ & $\begin{array}{l}\text { Current density/ } \\
\mathrm{mA} \\
\mathrm{g}^{-1}\end{array}$ & $\begin{array}{l}\text { Cycles (times)/ } \\
\text { capacity } \\
\left(\mathrm{mA} \mathrm{h} \mathrm{g}^{-1}\right)\end{array}$ & References \\
\hline $\mathrm{V}_{2} \mathrm{O}_{5}$ powder & Nanorod & 335 & 10 & $50 / 260$ & 53 \\
\hline $\mathrm{NH}_{4} \mathrm{VO}_{3}$ & Nanorod & 418.8 & 50 & $50 / 180.5$ & 54 \\
\hline $\mathrm{NH}_{4} \mathrm{VO}_{3}$ & Nanorod & 265 & 29.4 & $\sim$ & 55 \\
\hline $\mathrm{V}_{2} \mathrm{O}_{5}$ powder & Nanorod & 260 & 10 & $30 / 240$ & 56 \\
\hline $\mathrm{LiV}_{3} \mathrm{O}_{8}$ powder & Nanorod & 388 & 58.8 & $70 / 325$ & 58 \\
\hline $\mathrm{V}_{2} \mathrm{O}_{5}$ powder & Nanorod & 292 & 100 & $20 / 286$ & 59 \\
\hline $\mathrm{V}_{2} \mathrm{O}_{5}$ powder & Nanorod & 338 & 101 & $50 / 326$ & 60 \\
\hline Ammonium metavanadate & Nanowire & 390 & 30 & $50 / 201$ & 65 \\
\hline Cassava starch & Nanowire & 209 & 60 & $30 / 198$ & 69 \\
\hline Vanadyl acetylacetonate & Nanowire & 225 & 58.8 & $60 / 125$ & 144 \\
\hline $\mathrm{VOSO}_{4} \cdot n \mathrm{H}_{2} \mathrm{O}$ & Nanotube & 300 & $\sim$ & $10 / 160$ & 72 \\
\hline $\mathrm{V}_{2} \mathrm{O}_{5}$ powder & Nanotube & 457 & 30 & $10 / 270$ & 73 \\
\hline $\mathrm{V}_{2} \mathrm{O}_{5}$ powder & Nanotube & 284.7 & 60 & $10 / 218.5$ & 74 \\
\hline $\mathrm{V}_{2} \mathrm{O}_{5}$ powder & Nanotube & 204 & 20 & $4 / 87.7$ & 75 \\
\hline $\mathrm{V}_{2} \mathrm{O}_{5}$ powder & Nanotube & 275.2 & 58.8 & $50 / 204$ & 76 \\
\hline $\mathrm{V}_{2} \mathrm{O}_{5} \cdot n \mathrm{H}_{2} \mathrm{O}$ & Nanofiber & 370 & 800 & $40 / 347$ & 77 \\
\hline Vanadium acetylacetonate & Nanofiber & 310 & 29.4 & $50 / 229$ & 78 \\
\hline $\mathrm{V}_{2} \mathrm{O}_{5}$ powder & Nanofiber & 139 & 800 & $100 / 133.9$ & 79 \\
\hline $\begin{array}{l}\text { Vanadium hydroxylamido } \\
\text { complex }\end{array}$ & Nanofiber & 440 & 64 & $30 / 200$ & 80 \\
\hline $\mathrm{V}_{2} \mathrm{O}_{5}$ powder & Nanobelt & 142 & 50 & $100 / 141$ & 81 \\
\hline $\mathrm{NH}_{4} \mathrm{VO}_{3}$ & Nanobelt & 288 & 50 & $50 / 246$ & 82 \\
\hline $\mathrm{V}_{2} \mathrm{O}_{5}$ powder & Nanobelt & 127.4 & 60 & $200 / 114.7$ & 83 \\
\hline $\mathrm{V}_{2} \mathrm{O}_{5}$ powder & Nanobelt & 281 & 58.8 & $50 / 242$ & 84 \\
\hline Ammonium metavanadate & Nanorod & 287 & 100 & $50 / 207$ & 140 \\
\hline $\mathrm{NH}_{4} \mathrm{VO}_{3}$ & Nanosheet & 185.6 & 294 & $50 / 179.5$ & 85 \\
\hline $\mathrm{V}_{2} \mathrm{O}_{5}$ crystal & Nanosheet & 290 & 59 & $50 / 274$ & 86 \\
\hline $\mathrm{V}_{2} \mathrm{O}_{5}$ powder & Nanosheet & 108 & 2940 & $200 / 104$ & 87 \\
\hline $\mathrm{V}_{2} \mathrm{O}_{5}$ powder & Nanosheet & $264(3)$ & 50 & $50 / 237$ & 88 \\
\hline $\mathrm{NH}_{4} \mathrm{VO}_{3}$ & Nanosheet & 147 & 100 & $100 / 144$ & 89 \\
\hline $\mathrm{V}_{2} \mathrm{O}_{5}$ powder & Nanosheet & 135 & 300 & $200 / 126.6$ & 91 \\
\hline $\mathrm{V}_{2} \mathrm{O}_{5}$ powder & Nanosheet & 251 & 500 & $100 / 206$ & 92 \\
\hline Vanadium oxytriisopropoxide & Nanosheet & 277 & 300 & $100 / 211$ & 93 \\
\hline $\mathrm{NH}_{4} \mathrm{VO}_{3}$ & Nanosheet & 310 & 29.4 & $50 / 234$ & 94 \\
\hline $\mathrm{NH}_{4} \mathrm{VO}_{3}$ & Hollow porous microspheres & 283 & 100 & $60 / 217$ & 95 \\
\hline $\mathrm{NH}_{4} \mathrm{VO}_{3}$ & Hollow spheres & 273 & 58.8 & $50 / 189$ & 96 \\
\hline $\mathrm{NH}_{4} \mathrm{VO}_{3}$ & Hollow microspheres & 241 & 300 & $60 / 190$ & 97 \\
\hline$\left[\mathrm{V}(\mathrm{acac})_{3}\right]$ & Hollow microspheres & 286.4 & 58.8 & $\sim$ & 98 \\
\hline $\mathrm{V}_{2} \mathrm{O}_{5}$ powder & Hollow sphere arrays & About 292 & 147 & $300 / 285$ & 99 \\
\hline $\mathrm{V}_{2} \mathrm{O}_{5}$ powder & Porous microspheres & 390 & 40 & $50 / 200$ & 100 \\
\hline $\mathrm{NH}_{4} \mathrm{VO}_{3}$ & $\begin{array}{l}\text { Hierarchical and porous } \\
\text { microspheres }\end{array}$ & 141 & 147 & $100 / 102$ & 101 \\
\hline $\mathrm{NH}_{4} \mathrm{VO}_{3}$ & Porous hierarchical octahedrons & 135 & 100 & $60 / 141$ & 102 \\
\hline Vanadium oxytriisopropoxide & Porous microspheres & 146.3 & 75 & $100 / 130$ & 103 \\
\hline $\mathrm{V}_{2} \mathrm{O}_{5}$ powder & Hierarchical microspheres & 275 & 294 & $200 / 243$ & 104 \\
\hline $\mathrm{NH}_{4} \mathrm{VO}_{3}$ & Hierarchical 3D microspheres & 275 & 58.8 & $50 / 243$ & 105 \\
\hline $\mathrm{V}_{2} \mathrm{O}_{5}$ powder & Hierarchical 3D microstructures & 274 & 300 & $50 / 219$ & 106 \\
\hline Vanadium oxytriisopropoxide & Hollow microflowers & 277 & 300 & $100 / 211$ & 107 \\
\hline $\mathrm{VO}(\mathrm{acac})_{2}$ & Hierarchical microflowers & 285 & 29.4 & $50 / 249$ & 108 \\
\hline $\mathrm{NH}_{4} \mathrm{VO}_{3}$ & Hierarchical microflowers & 145 & 200 & $150 / 128$ & 109 \\
\hline Vanadium(Iv) acetylacetone & Yolk-shell microspheres & 280 & 58.8 & $30 / 220$ & 110 \\
\hline Vanadium(Iv) acetylacetone & Hierarchical microspheres & $270.5(2)$ & 300 & $80 / 166.8$ & 111 \\
\hline Vanadium oxytriisopropoxide & Hollow microspheres & 291 & 100 & $6 / 254$ & 112 \\
\hline Vanadium oxytriisopropoxide & Box & 119 & 1500 & $400 / 111$ & 113 \\
\hline $\mathrm{VOC}_{2} \mathrm{O}_{4}$ & Hollow microspheres & 256 & 300 & $50 / 227$ & 114 \\
\hline $\mathrm{NH}_{4} \mathrm{VO}_{3}$ & Multi-shelled & 447.9 & 1000 & $100 / 402.4$ & 115 \\
\hline $\mathrm{V}_{2} \mathrm{O}_{5}$ & Hollow microspheres & $137(2)$ & 300 & $50 / 128$ & 116 \\
\hline
\end{tabular}

prepared by electrospinning, and the surface of the nanowires was bonded with nanorods with a diameter of about $50 \mathrm{~nm}$ and length of about $100 \mathrm{~nm}$. The electrospun composite nanowires were then annealed at $480{ }^{\circ} \mathrm{C}$ in air for $3 \mathrm{~h}$ to obtain vanadium oxide nanowires. After annealing, the nanowires could retain their length as continuous structures, while the diameter 


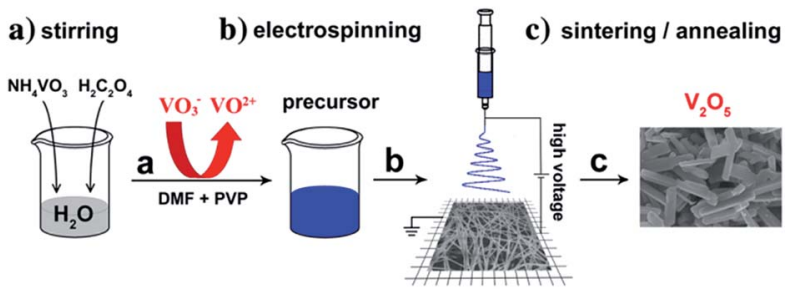

Fig. 3 Electrospinning reaction process for $\mathrm{V}_{2} \mathrm{O}_{5}$ micro/nanorods. ${ }^{54}$

decreased to 100-200 nm. Notably, it was found that the ultralong vanadium oxide nanowires were constructed from attached nanorods of diameter of approximately $50 \mathrm{~nm}$ and length of $100 \mathrm{~nm}$. In the voltage window of $1.75-4.0 \mathrm{~V}$, the cathode obtained an initial discharge capacity of $390 \mathrm{~mA} \mathrm{~h} \mathrm{~g}^{-1}$ and $201 \mathrm{~mA} \mathrm{~h} \mathrm{~g}^{-1}$ during the first and 50th cycles at a current density of $30 \mathrm{~mA} \mathrm{~g}^{-1}$, respectively. Moreover, the as-prepared ultralong hierarchical vanadium oxide nanowires were found to offer high charge/discharge capacities and improved cycling stability.

Velazquez et al. ${ }^{66}$ prepared $\mathrm{V}_{2} \mathrm{O}_{5}$ nanowire arrays on silicon substrates by the thermal evaporation method. The nanowires obtained were single crystalline and highly oriented with their lengths and substrate coverage controlled by the duration of the reaction, reaction temperature, and flow velocity. The growth of these nanowire arrays has great value in the fabrication of novel battery architectures based on individual nanowires. Ramasami et al. ${ }^{69}$ synthesised a $\mathrm{V}_{2} \mathrm{O}_{5}$ NWC by the combustion method using cassava starch. The noteworthy features of the synthesis are that it is a simple and time-saving process, gives high yield, and uses naturally occurring fuel that doubles up as a template for the growth of nanowires/nanorods. The schematic representation of the nanowire cluster formation is given in Fig. 4. The $\mathrm{V}_{2} \mathrm{O}_{5}$ NWC exhibited an initial discharge and charge capacity of 209 and $206 \mathrm{~mA} \mathrm{~h} \mathrm{~g}^{-1}$, respectively with a corresponding coulombic efficiency of $96 \%$ and the obtained discharge capacity at the 30th cycle was $198 \mathrm{~mA} \mathrm{~h} \mathrm{~g}^{-1}$. The discharge capacity fading was found be negligible (with a small fading rate of $0.1 \%$ per cycle) from the beginning to the 50th cycle. The capacity retention in the 30th cycle was $95 \%$ with respect to the first cycle capacity. Compared to previous

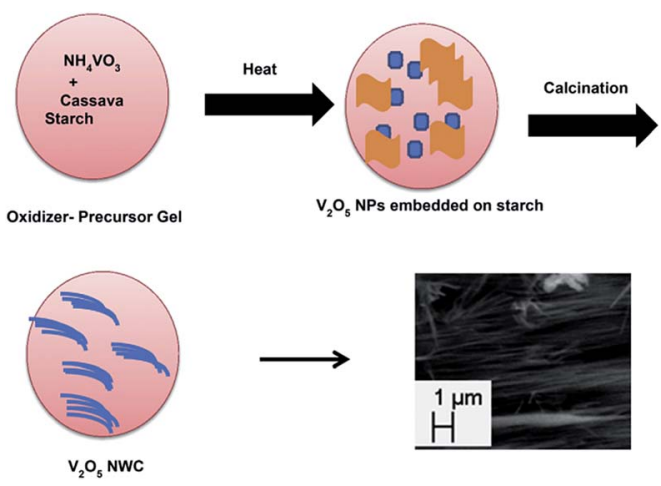

Fig. 4 Illustration of $\mathrm{V}_{2} \mathrm{O}_{5}$ NWC formation. ${ }^{69}$ literature, ${ }^{70,71}$ the as-prepared structure behaved as a superior material with respect to capacity and cycling stability.

2.1.3 $\mathrm{V}_{2} \mathrm{O}_{5}$ nanotubes. Compared with nanowires, the nanotubes have different contact areas, such as the inner and outer walls of the tube. The tubular structure can serve as a channel for filling the electrolyte, which is conducive to the promotion of ion transport. For the preparation of vanadium oxide nanotubes, the hydrothermal method is the most commonly used method. However, the fabrication of vanadium oxide nanotubes by hydrothermal synthesis is a very complicated process. In principle, nanotube arrays have larger surface areas than nanorod arrays. In addition, the tubes can operate as electrolyte-filled channels for faster transport of ions to the intercalation sites. As for the previous literature, template-based electrodeposition is a simple and efficient route for producing oxidic nanorods and nanotubes. Wang and co-workers ${ }^{72}$ used this method to prepare well-defined $\mathrm{V}_{2} \mathrm{O}_{5}$ nanotubes. Investigation of its electrochemical properties showed that the nanotube array possessed a high $\mathrm{Li}^{+}$intercalation capacity of $300 \mathrm{~mA} \mathrm{~h} \mathrm{~g}{ }^{-1}$. Although the capacities of the nanotube array decreased during cycling, the array achieved stabilized capacities within 10 cycles. The stabilized capacity of the nanotube was approximately $160 \mathrm{~mA} \mathrm{~h} \mathrm{~g}^{-1}$, which was $30 \%$ higher than the stabilized capacity of the film. The initial high capacity of the nanotube was obviously ascribed to the large surface area and short diffusion distances provided by the nanostructure. Cui et al. ${ }^{73}$ presented a convenient and controllable approach to synthesize lithium vanadium oxide nanotubes by a combined sol-gel reaction and hydrothermal treatment procedure.

Nadimicherla et al. ${ }^{75}$ synthesized $\mathrm{V}_{2} \mathrm{O}_{5}$ nanotubes and PEG surfactant $\mathrm{V}_{2} \mathrm{O}_{5}$ nanotubes by a simple hydrothermal method. Batteries using $\mathrm{V}_{2} \mathrm{O}_{5}$ nanotube electrodes showed an initial specific capacity $192 \mathrm{~mA} \mathrm{~h} \mathrm{~g}{ }^{-1}$, whereas the PEG surfactant $\mathrm{V}_{2} \mathrm{O}_{5}$ nanotubes exhibited a value of $204 \mathrm{~mA} \mathrm{~h} \mathrm{~g}^{-1}$. It was found that the PEG surfactant $\mathrm{V}_{2} \mathrm{O}_{5}$ nanotubes showed higher specific capacity at the initial stages and better stability as cycling progressed than the $\mathrm{V}_{2} \mathrm{O}_{5}$ nanotubes. This was due to the fact that polyethylene glycol occupied space between the vanadium oxide layers and contributed to the increase in $\mathrm{Li}^{+}$intercalation. In addition, polyethylene glycol had a relatively strong interaction with the vanadium oxide layer and had a complex interaction with $\mathrm{Li}^{+}$, thus effectively alleviating the electrostatic effect of the vanadium oxide layer and $\mathrm{Li}^{+}$. Li et al. ${ }^{76}$ chose commercial $\mathrm{V}_{2} \mathrm{O}_{5}$ powder and oxalic acid as the raw materials to obtain a low-cost inorganic vanadium oxalate solution as the electrospinning vanadium precursor, and adopted a facile electrospinning approach followed by annealing to fabricate porous $\mathrm{V}_{2} \mathrm{O}_{5}$ nanotubes. The schematic of the synthesis of the porous $\mathrm{V}_{2} \mathrm{O}_{5}$ nanotubes is shown in Fig. 5. The sample had highly porous and hollow nanostructures of the as-prepared $\mathrm{V}_{2} \mathrm{O}_{5}$, and the as-prepared $\mathrm{V}_{2} \mathrm{O}_{5}$ had diameters in the range of $300-500 \mathrm{~nm}$ with many pores on the surface. In the voltage window of $2.0-4.0 \mathrm{~V}$, the cathode obtained an initial discharge capacity of $275.2 \mathrm{~mA} \mathrm{~h} \mathrm{~g}^{-1}$ and $204 \mathrm{~mA} \mathrm{~h} \mathrm{~g}^{-1}$ during the first and 50th cycles at a current density of $58.8 \mathrm{~mA} \mathrm{~g}^{-1}$, respectively. Moreover, the coulombic efficiency maintained a value of $>96 \%$ throughout the cycling test.

2.1.4 $\mathbf{V}_{2} \mathrm{O}_{5}$ nanofibers. Compared with some other methods, electrospinning is a simple, cost-effective method 


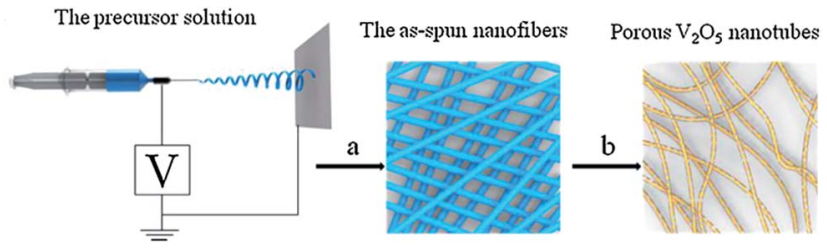

Fig. 5 Electrospinning preparation of porous $\mathrm{V}_{2} \mathrm{O}_{5}$ nanotubes: (a) electrospinning process; (b) annealing process. ${ }^{76}$

that enables the synthesis of nanofibers with diameters ranging from tens of nanometers to several micrometers and a large surface area-to-volume ratio. Yu et al. ${ }^{77}$ prepared mesoporous polycrystalline vanadium oxide nanofibers by electrospinning and high-temperature annealing with $\mathrm{V}_{2} \mathrm{O}_{5}, \mathrm{H}_{2} \mathrm{O}_{2}$ and polyvinylpyrrolidone (PVP) as the starting materials. The resulting nanofibers were $350 \mathrm{~nm}$ in diameter and consisted of a porous polycrystalline vanadium oxide with a specific surface area of $\sim 97 \mathrm{~m}^{2} \mathrm{~g}^{-1}$. The mesoporous $\mathrm{V}_{2} \mathrm{O}_{5}$ nanofibers demonstrated a significantly enhanced Li-ion storage capacity of above $370 \mathrm{~mA} \mathrm{~h} \mathrm{~g}{ }^{-1}$ and a high charge/discharge rate of up to $800 \mathrm{~mA} \mathrm{~g}^{-1}$ with little cyclic degradation. Such mesoporous $\mathrm{V}_{2} \mathrm{O}_{5}$ nanofibers allowed easy mass and charge transfer with sufficient freedom for volume change accompanying the lithium ion intercalation and de-intercalation. Cheah et al. ${ }^{78}$ fabricated single-phase polycrystalline high aspect ratio porous $\mathrm{V}_{2} \mathrm{O}_{5}$ nanofibers by a simple one-step electrospinning process using $\mathrm{V}_{2} \mathrm{O}_{5}$ precursor consisting of vanadium vanadyl acetylacetonate and poly(vinylpyrrolidone), followed by sintering at $400{ }^{\circ} \mathrm{C}$ for $15 \mathrm{~min}$. Porosity was caused by the slight shrinkage of the fibers due to the thermal decomposition of the PVP polymer. In the voltage window of $1.75-4.0 \mathrm{~V}$, the cathode achieved an initial discharge capacity of $316 \mathrm{~mA} \mathrm{~h} \mathrm{~g}^{-1}$ and $158 \mathrm{~mA} \mathrm{~h} \mathrm{~g}^{-1}$ during the first and 50th cycles at $0.1 \mathrm{C}$ rate, respectively. In the voltage window of 2.0-4.0 $\mathrm{V}$, the cathode obtained an initial discharge capacity of $310 \mathrm{~mA} \mathrm{~h} \mathrm{~g}^{-1}$ and $229 \mathrm{~mA} \mathrm{~h} \mathrm{~g}^{-1}$ during the first and 50th cycles at $0.1 \mathrm{C}$ rate, respectively. Compared with in the $1.75-4 \mathrm{~V}$ voltage range, the specific capacity was greatly improved, which was due to the formation of nanoparticles connected to the nanofiber morphology.

Recently, Yan's group ${ }^{79}$ has proposed a modified, facile and effective electrospinning method to synthesize $\mathrm{V}_{2} \mathrm{O}_{5}$ nanofibers using commercial vanadium pentoxide as the precursor material, which is illustrated in Fig. 6. Compared with commercial $\mathrm{V}_{2} \mathrm{O}_{5}$ at various current densities, it is evident that $\mathrm{V}_{2} \mathrm{O}_{5}$ nanofibers exhibited much better rate capability and cyclic stability. For instance, at a current density of $100 \mathrm{~mA} \mathrm{~g}^{-1}$, the commercial $\mathrm{V}_{2} \mathrm{O}_{5}$ electrode exhibited continuous capacity fading in the initial four cycles. Interestingly, the specific capacity for $\mathrm{V}_{2} \mathrm{O}_{5}$ nanofibers was recovered after the cathode electrode worked at various current densities for 45 cycles; this performance was significantly better than that of the commercial $\mathrm{V}_{2} \mathrm{O}_{5}$ electrode. Dewangan et $a l .{ }^{80}$ proposed a simple mild one-step hydrothermal technique to prepare uniform $\mathrm{V}_{2} \mathrm{O}_{5}$ nanofiber bundles (NBs). The method used a vanadium(v) hydroxylamido complex as the vanadium source in the presence of $\mathrm{HNO}_{3}$. A bundle is made of an indefinite number of homogeneous $\mathrm{V}_{2} \mathrm{O}_{5}$ nanofibers

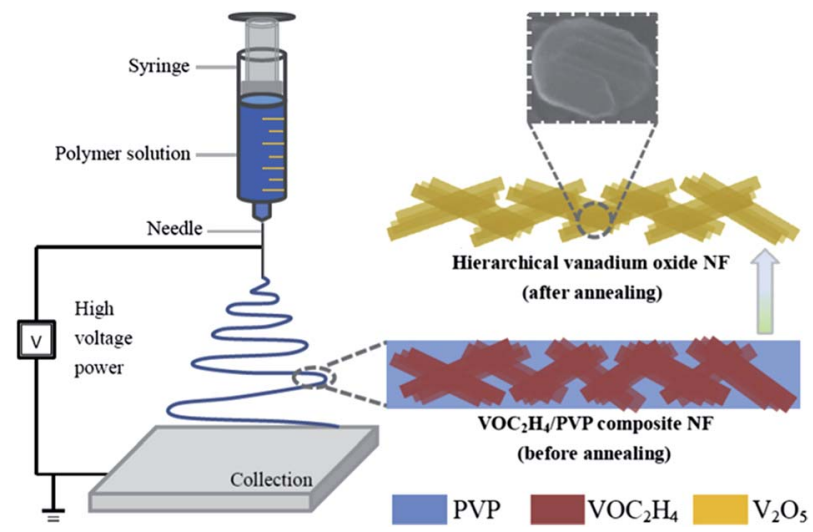

Fig. 6 Schematic showing the strategy for fabricating hierarchical $\mathrm{V}_{2} \mathrm{O}_{5}$ nanofibers. $^{79}$

with lengths up to several micrometres and widths ranging from 20 to $50 \mathrm{~nm}$. The as-prepared $\mathrm{V}_{2} \mathrm{O}_{5} \mathrm{NBs}$ displayed a high electrochemical performance in a non-aqueous electrolyte as a cathode material for lithium-ion batteries.

2.1.5 $\mathbf{V}_{2} \mathrm{O}_{5}$ nanobelts. Using one-dimensional vanadium pentoxide material, nanobelt structures have also been synthesized. Qin's group ${ }^{81}$ proposed a template-free hydrothermal method to synthesize ultra-thin $\mathrm{VO}_{2}(\mathrm{~B})$ nanobelt arrays with a thickness of about $10 \mathrm{~nm}$, which could be converted to $\mathrm{V}_{2} \mathrm{O}_{5}$ porous nanobelt arrays by calcining in air at $400{ }^{\circ} \mathrm{C}$. In the voltage window of 2.5-4.0 V, a specific discharge capacity of $146 \mathrm{~mA} \mathrm{~h} \mathrm{~g}^{-1}$ at the 50th cycle as achieved, which is very close to the theoretical capacity of $\mathrm{V}_{2} \mathrm{O}_{5}$ crystallite electrodes $\left(147 \mathrm{~mA} \mathrm{~h} \mathrm{~g}^{-1}\right)$. The coulombic efficiency was nearly $100 \%$, suggesting the good reversibility of the Li-ion insertion/deinsertion process. Even at a much higher current density of $1000 \mathrm{~mA} \mathrm{~g}^{-1}$, a specific discharge capacity of $130 \mathrm{~mA} \mathrm{~h} \mathrm{~g}{ }^{-1}$ and capacity retention of $128 \mathrm{~mA} \mathrm{~h} \mathrm{~g}^{-1}$ after 100 cycles could be achieved. The capacity fading rate was calculated to be $0.015 \%$ per cycle, suggesting superior capacity retention capability. The excellent rate performance and good capacity retention at various discharge rates are attributed to the interesting porous $\mathrm{V}_{2} \mathrm{O}_{5}$ nanobelt array structures. The nano-sized belts reduce the distance of Li-ion diffusion and electron transportation. Moreover, the porous structures of the nanobelt arrays facilitate electrolyte penetration and increase the contact area between the active material and the electrolyte. Furthermore, the porous structure might also be of advantage to accommodate the volume variations during Li-ion intercalation and de-intercalation. Niu et al. ${ }^{82}$ successfully fabricated hierarchical $\mathrm{V}_{2} \mathrm{O}_{5}$ nanobelts by an economical and facile hydrothermal strategy followed by annealing treatment, as illustrated in Fig. 7 . The self-template synthesized hierarchical nanobelt assembled by plate-like nanocrystallines had an open structure with tiny haircuts and a large contract area. When the battery was cycled between 2 and $4 \mathrm{~V}$ at a current density of $50 \mathrm{~mA} \mathrm{~g}^{-1}$, the initial discharge capacity was $288 \mathrm{~mA} \mathrm{~h} \mathrm{~g}^{-1}$. The discharge capacity was $246 \mathrm{~mA} \mathrm{~h} \mathrm{~g}^{-1}$ at the end of the 50th cycle, with a capacity retention of $85.4 \%$. The good performance of the hierarchical nanobelts can be attributed to their advantages of a hierarchical structure, which is open with tiny haircuts, providing more 


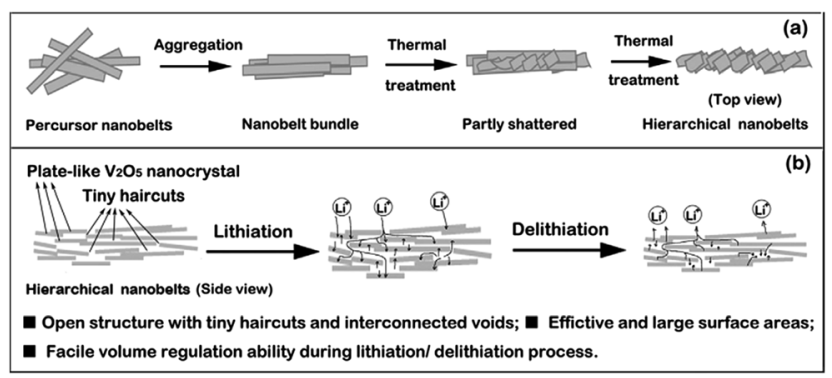

Fig. 7 (a) Schematic of possible formation process of $\mathrm{V}_{2} \mathrm{O}_{5}-\mathrm{HNbs}$, and (b) advantages of hierarchical nanobelt structures when applied in lithium-ion batteries. ${ }^{82}$

pathways for the immersion of liquid electrolyte. Also, these nanobelts have a large and effective surface area, facilitating the electrochemical reaction between the active material and the electrolyte and enable easy strain relaxation to accommodate volume variations during lithiation/delithiation, thus enhancing the structural stability and cyclability.

Wang and co-workers ${ }^{83}$ fabricated a self-standing $\mathrm{V}_{2} \mathrm{O}_{5}$ nanobelt electrode free of conductive agents, binders and current collectors by a simple one-step hydrothermal reaction. The length of the $\mathrm{V}_{2} \mathrm{O}_{5}$ nanobelts was up to several hundreds of micrometers and the thickness was around $40 \mathrm{~nm}$. The asprepared sample demonstrated better cycling performance than commercial conventional $\mathrm{V}_{2} \mathrm{O}_{5}$ electrodes with a high reversible capacity of $114.4 \mathrm{~mA} \mathrm{~h} \mathrm{~g}^{-1}$ after 200 charge-discharge cycles. The superior cycling performance of the nanobelt network electrode can be attributed to the excellent structural stability provided by the crosslinked nanobelt network. Rui et al. ${ }^{84}$ demonstrated a cost-effective and green process for the large-scale synthesis of single-crystalline $\mathrm{V}_{2} \mathrm{O}_{5}$ nanobelts (in kilogram scale) under ambient conditions by simply vigorous stirring the commercially available $\mathrm{V}_{2} \mathrm{O}_{5}$ powder in an aqueous $\mathrm{NaCl}$ solution. The as-prepared sample exhibited a higher reversible specific capacity of $242 \mathrm{~mA} \mathrm{~h} \mathrm{~g}^{-1}$ up to the 50th cycle with a capacity retention at $86 \%$.

For one-dimensional nanostructured materials, the preparation methods are mostly the sol-gel method and hydrothermal method, because these processes are simple and feasible and the requirements of the experimental conditions are not too high. Common nanofibers, nanowires, nanotubes, etc. to some extent have improved the performance of vanadium oxide as a cathode material, such as shortening the diffusion distance of lithium ions and electrons, improving the charge and discharge properties of the electrode material, or increasing the effective contact area to improve the storage of lithium ions and to improve the specific capacity of the material. The superior electrochemical performance of onedimensional nanostructures can be attributed to the following aspects.

First, one-dimensional nanostructures of $\mathrm{V}_{2} \mathrm{O}_{5}$ provide an effective electron transport pathway along the one-dimensional direction. Second, the one-dimensional nanostructures of $\mathrm{V}_{2} \mathrm{O}_{5}$ nanotubes with large electrode/electrolyte contact area and hierarchical porous channels provide short $\mathrm{Li}^{+}$diffusion distances. Finally, the existence of pyrolyzed carbon improves the conductivity of the one-dimensional nanostructures. These nanomaterials have a high specific surface area when they are prepared alone. However, when the electrode is prepared, the one-dimensional nanostructures are greatly reduced due to the large surface energy and low mechanical stability, likely resulting in agglomeration and a significant decrease in the specific surface area. Their initial discharge specific capacity will be higher in the charge and discharge tests, but they will produce significant capacity attenuation; also, the number of cycles will not be high in the long cycle performance without further improvement.

\section{$2.22 \mathrm{D}$ nanostructures}

Two-dimensional nanostructures increase the effective contact area between the electrolyte and the active material, increase the storage capacity of the lithium ions, and shorten the diffusion distance of the lithium ions to meet the demand for high charge and discharge and thus form an ideal structure for the rapid storage of lithium ions. However, the mechanical stress produced by the nanosheets in the process of circulation is easy to make the nanosheets overlap and thicken, weakening the effective contact area of the nanosheets. Therefore, the dispersibility of two-dimensional nanosheets is restricted as an excellent key factor for electrode material performance. It is helpful to effectively improve the electrochemical performance of two-dimensional vanadium pentoxide nanosheets electrode materials by introducing a conductive agent between the nanosheet and increasing the spacing of the nanosheets. Huang et $a l .{ }^{85}$ developed an additive-free ultrasonic method with subsequent thermal decomposition to synthesize $\mathrm{V}_{2} \mathrm{O}_{5}$ selfassembled nanosheets. The loose $\mathrm{V}_{2} \mathrm{O}_{5}$ nanosheets were stacked as 4-6 layers and each layer ( $\sim 50 \mathrm{~nm}$ in thickness) was assembled using abundant nanoparticles. The as-prepared sample delivered a reversible capacity of $185.6 \mathrm{~mA} \mathrm{~h} \mathrm{~g}^{-1}$ and $179.5 \mathrm{~mA} \mathrm{~h} \mathrm{~g}^{-1}$ at the 1st and 50th cycles, respectively, corresponding to a capacity retention of $96.7 \%$. However, $\mathrm{NPs}_{2} \mathrm{O}_{5}$ only had a reversible capacity of $121.4 \mathrm{~mA} \mathrm{~h} \mathrm{~g}^{-1}$. After 50 cycles, $87.4 \%$ of the capacity $\left(\sim 106.1 \mathrm{~mA} \mathrm{~h} \mathrm{~g}^{-1}\right)$ was retained. All the results demonstrated that the unique structure of SANs $\mathrm{V}_{2} \mathrm{O}_{5}$ resulted in improved rate performance and high cycling stability at higher current densities, which was expected to satisfy the requirement of a long cycle life for LIBs.

Rui's group ${ }^{86}$ proposed a liquid phase separation method to prepare ultrathin $\mathrm{V}_{2} \mathrm{O}_{5}$ nanosheets. In the range of $2.05-4 \mathrm{~V}$, the first reversible specific discharge capacity of was $290 \mathrm{~mA} \mathrm{~h} \mathrm{~g}^{-1}$ at $0.2 \mathrm{C}$. When the rate increased to $50 \mathrm{C}$, the capacity was $117 \mathrm{~mA} \mathrm{~h} \mathrm{~g}^{-1}$. This is mainly due to the deposition of lithium ions on the surface of these ultra-thin nanosheets; ultra-thin nanosheets shorten the embedded path of lithium ions to meet the requirements of rapid charge and discharge. An et al. ${ }^{87}$ successfully prepared ultrathin $\mathrm{V}_{2} \mathrm{O}_{5}$ nanosheets through a supercritical solvothermal reaction followed by annealing, as illustrated in Fig. 8. As a cathode material for lithium batteries, the ultrathin $\mathrm{V}_{2} \mathrm{O}_{5}$ nanosheets exhibited a capacity of $108 \mathrm{~mA} \mathrm{~h} \mathrm{~g}^{-1}$ at a high rate of up to $10 \mathrm{C}$ at $2.4-4 \mathrm{~V}$ and excellent 


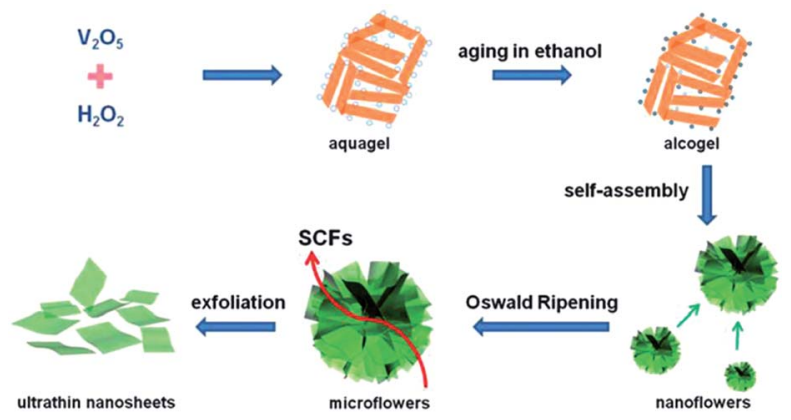

Fig. 8 Schematic illustration of the procedure for fabricating the ultrathin vanadium oxide nanosheets. ${ }^{87}$

cyclability with little capacity loss after 200 cycles. The enhanced rate performance is attributed to the shortened diffusion distance and the increased electrode-electrolyte contact area of the ultrathin nanosheet structure. Subsequently, Liang's group ${ }^{88}$ fabricated nanosheet-structured vanadium pentoxide by a sol-gel method. As a cathode material, the $\mathrm{V}_{2} \mathrm{O}_{5}$ nanosheets exhibited enhanced cycling stability and rate capability. The as-prepared NSs showed better lithium storage properties than commercial $\mathrm{V}_{2} \mathrm{O}_{5}$, with a reversible capacity of $237 \mathrm{~mA} \mathrm{~h} \mathrm{~g}^{-1}$ after 50 cycles.

Song et al. ${ }^{89}$ prepared mesoporous $\mathrm{V}_{2} \mathrm{O}_{5}$ nanosheets by a hydrothermal method followed by instantaneous heating and calcination in air, as illustrated in Fig. 9. The as-prepared $\mathrm{V}_{2} \mathrm{O}_{5}$ nanosheets were composed of several well-defined porous nanosheets that assembled themselves together and formed a highly mesoporous nanosheet structure. In the voltage window of $2.5-4.0 \mathrm{~V}$, the cathode obtained a reversible capacity of $147 \mathrm{~mA} \mathrm{~h} \mathrm{~g}^{-1}$ in the 2nd cycle and $144 \mathrm{~mA} \mathrm{~h} \mathrm{~g}^{-1}$ in the first and 100th cycles at a current density of $100 \mathrm{~mA} \mathrm{~h} \mathrm{~g}^{-1}$. The good performance of mesoporous $\mathrm{V}_{2} \mathrm{O}_{5}$ nanosheets can be attributed to the advantages of this novel structure. Xu's group ${ }^{90}$ developed a one-step polymer-assisted chemical solution method to synthesize two-dimensional $\mathrm{V}_{2} \mathrm{O}_{5}$ sheet networks. This unique network structure provided an interconnected transportation pathway for lithium ions. The as-prepared sample exhibited a high capacity of about $300 \mathrm{~mA} \mathrm{~h} \mathrm{~g}^{-1}$ at a current density of $100 \mathrm{~mA} \mathrm{~g}^{-1}$. Recently, Liang et al..$^{91}$ proposed a bottom-up solvothermal method to synthesize ultra-large $\mathrm{V}_{2} \mathrm{O}_{5}$ nanosheets. The thickness of the large nanosheet was around $4 \mathrm{~nm}$ and the thickness of the parallel stacked nanosheets was about $3-5 \mathrm{~nm}$. Moreover, the cathode obtained a capacity of is $135 \mathrm{~mA} \mathrm{~h} \mathrm{~g}^{-1}$ in the 2nd cycle and a retention of $93.8 \%$ after 200 cycles at a current density of $100 \mathrm{~mA} \mathrm{~h} \mathrm{~g}^{-1}$. The coulombic efficiency was

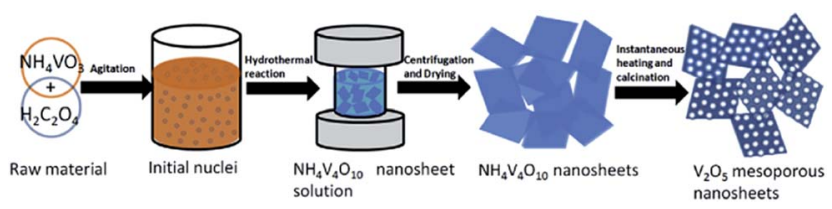

Fig. 9 Schematic of the synthesis route of $\mathrm{V}_{2} \mathrm{O}_{5}$ mesoporous nanosheets in this work. ${ }^{89}$ close to $100 \%$ during the whole discharge/charge process. The excellent rate performance and remarkable cyclic stability are due to the structural advantages of this uniform 2D ultrathin nanosheet with an ultra-large lateral size: (1) the void space between the nanosheets can facilitate the penetration of electrolyte; (2) the ultra-thin feature can reduce $\mathrm{Li}^{+}$ion diffusion distance and electron transportation distance; (3) the flexible nanosheets can accommodate the volume changes caused by repeated lithium ion insertion and removal; and (4) the ultralarge nanosheets and layer-by-layer stacking structures can better maintain the integrity of the nanosheet electrodes. Li and co-workers ${ }^{92}$ prepared $2 \mathrm{D}$ leaf-like $\mathrm{V}_{2} \mathrm{O}_{5}$ nanosheets by a novel and facile green method. The unique nanoscale characteristics, including 2D morphology, hierarchical porous structure, and large specific surface, of these $2 \mathrm{D}_{2} \mathrm{O}_{5}$ nanosheets led to superior electrochemical performance in terms of their specific capacity, rate capability, and cyclability.

As the cathode material of the two-dimensional nanosheet, lamellar nanostructures have a large specific surface area and good structural flexibility, which provide a larger space for the diffusion of ions and can adapt to the volume changes in the cathode material during the lithiation and de-lithiation of lithium, thus improving the cycling stability of the cathode material. If a conductive active material such as carbon nanotubes and carbon black is compounded in the structural material of the nanosheets, it is possible to prevent not only the agglomeration of the nanosheets but also the high conductivity of the active material. At the same time, this reduces the impedance of ions on nanosheets and makes the lithium ions diffuse faster in the electrode material, thus obtaining excellent charge and discharge performance, which is helpful to improve the electrochemical performance of the two-dimensional nanosheet cathode materials. Compared with onedimensional nanostructured materials, the initial discharge specific capacity of the nanosheets is significantly lower. The reason may be that the vanadium oxide nanosheets are agglomerated during the charge and discharge process, resulting in a significant reduction in the effective contact area, which cannot effectively maintain the high specific surface area of the nanosheets. As with the one-dimensional vanadium pentoxide nanostructures, the long-term cycling performance of nanosheet cathode materials reported in the relevant literature has not improved.

\subsection{D nanostructures}

In recent years, three-dimensional structures have attracted considerable attention as an important role of electrode materials. Compared with low-dimensional nanomaterials, threedimensional nanostructured materials with desired morphologies have been prepared for their superior electrochemical properties as they not only inherit the advantages of lowdimensional nanomaterials, but also maintain the structural stability of the electrode during the $\mathrm{Li}^{+}$intercalation and deintercalation process. In addition, the three-dimensional nanostructures are self-supporting, and the nanocomposites are not prone to agglomeration during circulation. Also, the 
pore structure of the prepared electrode material is maintained for a long time. Thus, under the same electrochemical cycling test, vanadium pentoxide electrode materials have a threedimensional or graded structure exhibiting better electrochemical performance than the low-dimensional electrode materials and better cycling stability. Compared with onedimensional nanowires, nanotubes and two-dimensional nanosheets, the three-dimensional structure of vanadium oxide shows a variety of peculiar morphologies, such as loose nanoscale structures, and antennaed nanospheres, similar to the structure of sea urchins; these strange nanostructures can generally be prepared by adding a templating agent, such as dodecylamine and dodecyl mercaptan. For the threedimensional nanomaterials of vanadium pentoxide, the most commonly used preparation method is the solvothermal method.

2.3.1 Hollow porous nanostructures. A few years ago, Mai et al. ${ }^{95}$ used carbon microspheres as the template to synthesize 3D hollow porous $\mathrm{V}_{2} \mathrm{O}_{5}$ quasi-microspheres by a facile solvothermal and annealing method. By selecting an appropriate voltage window, the as-prepared sample exhibited good cycling performance of $283 \mathrm{~mA} \mathrm{~h} \mathrm{~g}^{-1}$ at a current density of $100 \mathrm{~mA} \mathrm{~g}^{-1}$. The excellent electrochemical performance is attributed to the nanosized building blocks of the $3 \mathrm{D}_{2} \mathrm{O}_{5}$ hollow porous structure, which provides a short Li-ion diffusion distance, effective strain relaxation, and large active contact area. By using P123 surfactant as the soft template, Zhang's group ${ }^{96}$ successfully obtained three-dimensional $\mathrm{V}_{2} \mathrm{O}_{5}$ hollow spheres by a simple synthesis strategy combining the solvothermal treatment and subsequent thermal annealing. As shown in Fig. 10a, the $\mathrm{V}_{2} \mathrm{O}_{5}$ precursor was composed of threedimensional microspheres with diameters in the range of two to three microns. The reversible capacity was $189 \mathrm{~mA} \mathrm{~h} \mathrm{~g}^{-1}$ at the end of 50 charge-discharge cycles. It also exhibited satisfactory lithium-ion storage performance. In another similar system, Uchaker and co-workers ${ }^{97}$ synthesized nanostructured $\mathrm{V}_{2} \mathrm{O}_{5}$ hollow microspheres via a solvothermal route followed by thermal treatment. Previously, Cao et al. ${ }^{98}$ prepared selfassembled $\mathrm{V}_{2} \mathrm{O}_{5}$ nanorods into microspheres by a mediated polyol process. The method represents a substantial simplification over more conventional methods such as electrostatic spray deposition or thermal evaporation. The as-prepared sample also exhibited good electrochemical performance when they were used as the cathode material in lithium-ion batteries.

Chen and co-workers ${ }^{99}$ developed a facile polystyrene sphere template-assisted electrodeposition method for the fabrication of porous multilayer $\mathrm{V}_{2} \mathrm{O}_{5}$ hollow sphere arrays on graphite paper substrates. We could clearly see that a 3D porous hollow sphere structure was well formed and the individual hollow sphere exhibited a size of $\sim 500 \mathrm{~nm}$ (Fig. 10b). We also can reach the conclusion that it is reasonable for the obtained porous multilayer $\mathrm{V}_{2} \mathrm{O}_{5}$ hollow sphere arrays to possess impressive porous systems, as these systems will be beneficial for fast ion/ electron transfer, leading to fast reaction kinetics. This is especially important for high-rate LIB applications. Wu et al. ${ }^{112}$ reported the controllable synthesis of novel rattle-type $\mathrm{V}_{2} \mathrm{O}_{5}$

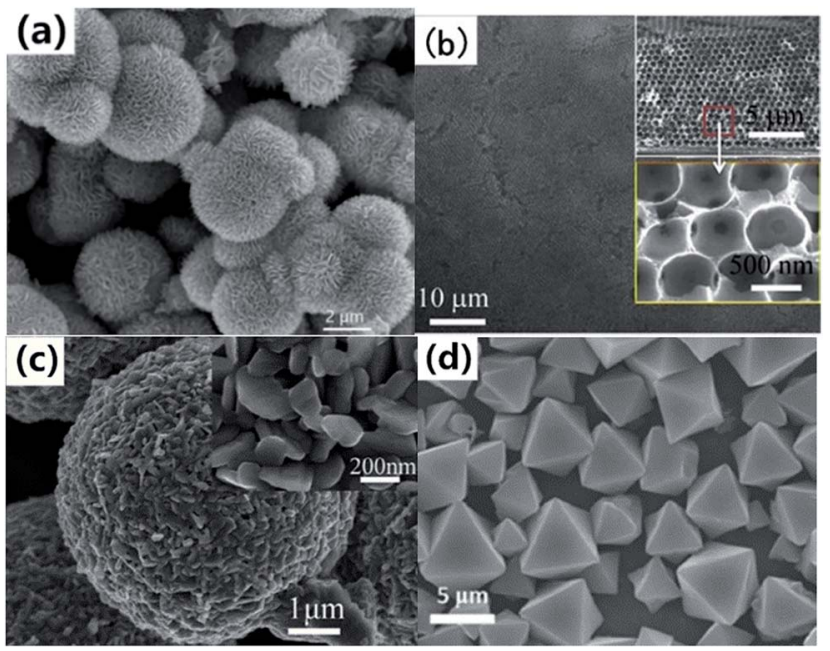

Fig. 10 (a) SEM images of $\mathrm{V}_{2} \mathrm{O}_{5}$ precursor. ${ }^{96}$ (b) Multilayer $\mathrm{V}_{2} \mathrm{O}_{5}$ hollow sphere arrays (cross-sectional SEM images in inset). ${ }^{99}$ (c) SEM images of the $\mathrm{V}_{2} \mathrm{O}_{5}$ product synthesized by annealing the corresponding $V E G$ precursors in air. ${ }^{101}$ (d) FESEM images of ammonium vanadium oxide octahedrons. ${ }^{102}$

hollow microspheres with the assistance of carbon colloidal spheres as hard templates. Carbon spheres@vanadiumprecursor (CS@V) core-shell composite microspheres were first prepared through a one-step solvothermal method. $\mathrm{V}_{2} \mathrm{O}_{5}$ hollow microspheres with various shell architectures could be obtained after removing the carbon microspheres by calcination in air. When evaluated as a cathode material for LIBs, the rattle-type $\mathrm{V}_{2} \mathrm{O}_{5}$ hollow microspheres exhibited superior cycling stability and rate capability. Pan and co-workers ${ }^{114}$ proposed a one-pot template-free solvothermal method for the controllable synthesis of uniform $\mathrm{VO}_{2}$ microspheres with different complex interiors, including yolk-shell and multi-shell structures. The $\mathrm{VO}_{2}$ hollow spheres could be readily transformed into $\mathrm{V}_{2} \mathrm{O}_{5}$ hollow spheres without any structural deformation by calcination in air. The resulting $\mathrm{V}_{2} \mathrm{O}_{5}$ hollow microspheres exhibited a high initial reversible capacity of $256 \mathrm{~mA} \mathrm{~h} \mathrm{~g}^{-1}$ at a current density of $300 \mathrm{~mA} \mathrm{~g}^{-1}$ and good cycling performance over 50 cycles. Pan et al. ${ }^{116}$ also reported the synthesis of hierarchical nanosheet-constructed hollow V-glycolate microspheres by a template-free method using a cost-effective $\mathrm{VOC}_{2} \mathrm{O}_{4}$ solution as the precursor. After calcination in air, $\mathrm{V}_{2} \mathrm{O}_{5}$ hollow hierarchical microspheres with well-preserved structures could be obtained and they were found to exhibit superior rate capability and cycling stability as cathode materials for LIBs.

2.3.2 Hierarchical and porous nanostructures. Wang and co-workers ${ }^{101}$ developed a reflux approach followed by annealing to synthesise hierarchical and porous $\mathrm{V}_{2} \mathrm{O}_{5}$ microspheres. As is shown in Fig. 10c, the $\mathrm{V}_{2} \mathrm{O}_{5}$ microsphere had rough and textured surfaces with porous structures. The superior $\mathrm{Li}^{+}$ storage performance of the hierarchical and porous $\mathrm{V}_{2} \mathrm{O}_{5}$ microspheres could be mainly ascribed to the improved electrode/electrolyte interface, reduced $\mathrm{Li}^{+}$diffusion paths, and relieved volume variation during lithiation and delithiation 
processes. An et al. ${ }^{\mathbf{1 0 2}}$ reported the synthesis of porous $\mathrm{V}_{2} \mathrm{O}_{5}$ hierarchical octahedrons via a solid-state conversion process. The surface of the octahedrons was smooth, with a diameter range of 3-6 $\mu \mathrm{m}$ (Fig. 10d). Zhang et al. ${ }^{103}$ synthesized novel 3D porous $\mathrm{V}_{2} \mathrm{O}_{5}$ hierarchical microspheres by a solvothermal method and subsequent calcination (Fig. 11). These 3D microspheres were constructed by nanoporous fibers, which endowed the electrode with shorter diffusion paths and higher conductivities. When evaluated as a cathode material for lithium-ion batteries, the $\mathrm{V}_{2} \mathrm{O}_{5}$ microspheres displayed relatively stable capacity retention at different current rates. They also showed excellent rate capability, with a capacity of $105 \mathrm{~mA} \mathrm{~h} \mathrm{~g}^{-1}$ at a 30C rate. The excellent electrochemical performance suggests that these unique hierarchical $\mathrm{V}_{2} \mathrm{O}_{5}$ microspheres can be a promising cathode material for lithium-ion batteries.

Recently, Dong et al. ${ }^{\mathbf{1 0 4}}$ developed a facile two-step strategy to synthesise $\mathrm{V}_{2} \mathrm{O}_{5}$ microspheres with a hierarchical structure. First, they synthesized a vanadium glycolate precursor by a facile template-free and polyol-mediated solvothermal method and then, they obtained $\mathrm{V}_{2} \mathrm{O}_{5}$ microspheres by thermal annealing. Bai and co-workers ${ }^{\mathbf{1 0 5}}$ facilely fabricated hierarchical 3D microspheres consisting of $2 \mathrm{D} \mathrm{V}_{2} \mathrm{O}_{5}$ (vanadium pentoxide) nanosheets by a low-temperature hydrothermal method. The novel hierarchical micro-/nano- $\mathrm{V}_{2} \mathrm{O}_{5}$ electrode exhibited excellent electrochemical performance in terms of high-energy and high-power applications owing to its unique structural properties. These hierarchical 3D micro-/nano- $\mathrm{V}_{2} \mathrm{O}_{5}$ possess many unique features advantageous for LIBs: (1) $2 \mathrm{D} \mathrm{V}_{2} \mathrm{O}_{5}$ nanosheets facilitate $\mathrm{Li}^{+}$ diffusion and electron transport; (2) hierarchical 3D micro-/nanocathode structures built up by $\mathrm{V}_{2} \mathrm{O}_{5}$ nanosheet spheres lead to close and sufficient contact between the electrolyte and activate materials and at the same time create a buffer to accommodate volume changes during discharge/charge process; and (3) microscale $\mathrm{V}_{2} \mathrm{O}_{5}$ spheres easily induce high cell packing density beneficial for high-power batteries. Pan et al. ${ }^{\mathbf{1 0 6}}$ developed a facile solvothermal method to synthesize hierarchical vanadium oxide with various nano/microstructures by simply varying the concentration of the precursor $\left(\mathrm{VOC}_{2} \mathrm{O}_{4}\right)$ solution. The $\mathrm{V}_{2} \mathrm{O}_{5}$

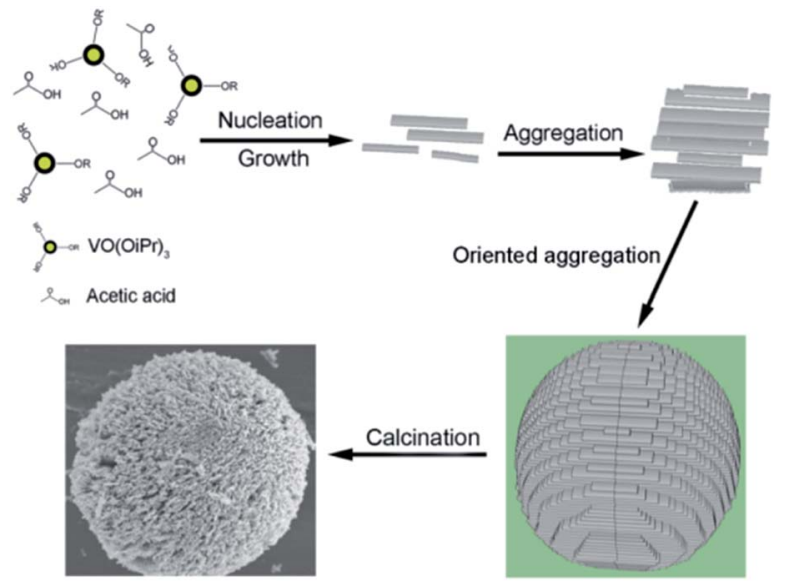

Fig. 11 Schematic of the formation of 3D porous $\mathrm{V}_{2} \mathrm{O}_{5}$ hierarchical microspheres. ${ }^{103}$ prepared by solvothermal method for $2 \mathrm{~h}$ showed good lithium storage properties with a high reversible capacity of $219 \mathrm{~mA} \mathrm{~h} \mathrm{~g}^{-1}$ after 50 cycles. In a follow-up study based on the above experimental results, $\mathrm{Pan}^{\mathbf{1 0 7}}$ synthesized hierarchically hollow microflowers composed of nanosheets via a one-pot solvothermal method. After annealing, the sample delivered a high initial discharge capacity of $277 \mathrm{~mA} \mathrm{~h} \mathrm{~g}^{-1}$, and the value slightly increased to $284 \mathrm{~mA} \mathrm{~h} \mathrm{~g}^{-1}$ in the second cycle probably due to improved electrolyte penetration. With a voltage window of 2.0$4.0 \mathrm{~V}$, the $\mathrm{V}_{2} \mathrm{O}_{5}$ hollow microflowers retained a remarkable reversible capacity of $211 \mathrm{~mA} \mathrm{~h} \mathrm{~g}^{-1}$ at the end of the 100th cycle.

Chen et al. ${ }^{109}$ successfully synthesized hierarchical $\mathrm{V}_{2} \mathrm{O}_{5}$ microflowers by a solvothermal reaction followed by a calcination process at $350{ }^{\circ} \mathrm{C}$. The product consisted of uniform flowerlike micro-spheres with an average size of around $2 \mu \mathrm{m}$. After annealing, the as-prepared hierarchical $\mathrm{V}_{2} \mathrm{O}_{5}$ microflowers showed good lithium storage properties with a high reversible capacity of $128 \mathrm{~mA} \mathrm{~h} \mathrm{~g}^{-1}$ after 150 cycles at a current density of $200 \mathrm{~mA} \mathrm{~g}^{-1}$. It was obvious that these capacities were higher than those of bulk $\mathrm{V}_{2} \mathrm{O}_{5}$. Ma et al. ${ }^{111}$ developed a facile templateless approach for the synthesis of various $\mathrm{V}_{2} \mathrm{O}_{5}$ hierarchical structures by calcining the solvothermally prepared $\mathrm{VO}_{2}$ with different morphologies and structures, which could be simply tailored by adjusting the solvothermal reaction duration. As the cathode materials for lithium-ion batteries, the electrode delivered reversible capacities of 119.2 and $87.3 \mathrm{~mA} \mathrm{~h} \mathrm{~g}^{-1}$ at high current densities of 2400 and $3600 \mathrm{~mA} \mathrm{~g}^{-1}$, respectively, as well as a capacity retention of $78.31 \%$ after 80 cycles at $1200 \mathrm{~mA} \mathrm{~g}^{-1}$. The excellent electrochemical performance could be attributed to the purity of the phase and the synergistic effect between the yolk-shell structure and hierarchical structure of the sub-microspheres. Thus, the three-dimensional nanostructures are more stable than the low-dimensional structures. Nanocomponents are less prone to agglomeration, and the active specific surface area can be maintained for a long time. As can be seen from Table 4, the three-dimensional structures show better cycling performance over prolonged cycling than the low-dimensional structures.

\section{3. $\mathrm{V}_{2} \mathrm{O}_{5}$-Based nanocomposites}

In addition to phase-pure $\mathrm{V}_{2} \mathrm{O}_{5}, \mathrm{~V}_{2} \mathrm{O}_{5}$-based nanocomposites have also been intensively studied as positive electrodes for LIBs. In this section, composites containing $\mathrm{V}_{2} \mathrm{O}_{5}$ and other materials will be discussed. In this part, $\mathrm{V}_{2} \mathrm{O}_{5}$ with different carbonaceous supports, including amorphous carbon, carbon nanotubes (CNTs), and graphene (Gr) will be surveyed (Table 4).

\section{1 $\mathrm{V}_{2} \mathrm{O}_{5}$ with amorphous carbon}

Amorphous carbon is an inexpensive, frequently used carbonaceous material that is easy to produce in industrial quantities. In LIB applications, amorphous carbon is used to produce a conductive compact outer layer on the surface of $\mathrm{V}_{2} \mathrm{O}_{5}$ NPs, which not only serves as a buffer layer to accommodate the volume expansion during cycling but also contributes to the formation of a stable solid electrolyte interface (SEI) layer. In 
Table 4 Electrochemical performance of carbonaceous materials used with $\mathrm{V}_{2} \mathrm{O}_{5}$ electrodes for Li-ion battery cathode materials

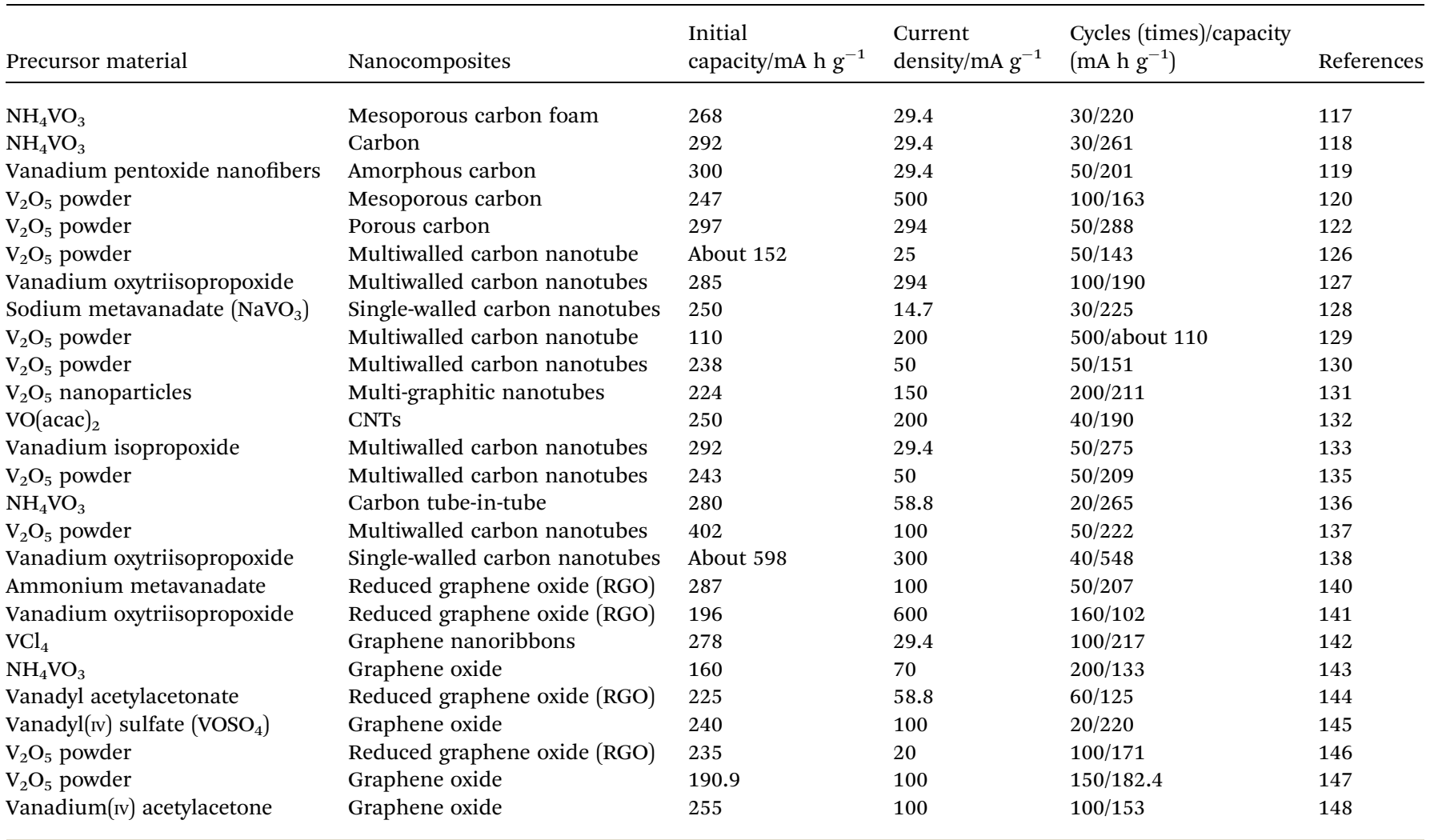

past research, the use of a carbon layer as a matrix buffer has exhibited superb properties. The carbon layer can also promote the electronic conductivity of the electrodes. As early as 2013, carbon-coated $\mathrm{V}_{2} \mathrm{O}_{5}$ nanoparticles ${ }^{117}$ produced via a facile and scalable method via the route illustrated in Fig. 12, demonstrated a first charge capacity of $268 \mathrm{~mA} \mathrm{~h} \mathrm{~g}^{-1}$ and a capacity of $220 \mathrm{~mA} \mathrm{~h} \mathrm{~g}^{-1}$ in the 30th cycle at a current density of $29.4 \mathrm{~mA} \mathrm{~g}^{-1}$. This carbon-coated $\mathrm{V}_{2} \mathrm{O}_{5}$ showed improved cycling stability and rate performance compared to nanosized $\mathrm{V}_{2} \mathrm{O}_{5}$. This approach can be extended to enhance the electrochemical performances of other alternative cathodes. Shin and coworkers $^{118}$ reported a facile and scalable method for the synthesis of carbon-coated $\mathrm{V}_{2} \mathrm{O}_{5}$ nanoparticles through a carboxylic acid-assisted sol-gel method and controlled calcination. $\mathrm{NH}_{4} \mathrm{VO}_{3}$ was used as the vanadium source. Oxalic acid $\left(\mathrm{C}_{2} \mathrm{O}_{4} \mathrm{H}_{2}\right)$, tartaric acid $\left(\mathrm{C}_{4} \mathrm{H}_{6} \mathrm{O}_{6}\right)$, and citric acid $\left(\mathrm{C}_{6} \mathrm{H}_{8} \mathrm{O}_{7}\right)$ were used as both the carbon sources and chelating/reducing agents

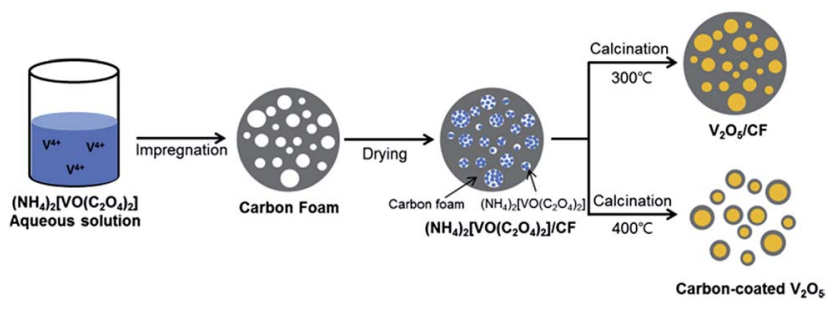

Fig. 12 Schematic of the preparation of carbon-fabricated $\mathrm{V}_{2} \mathrm{O}_{5}$ samples (CF300 and CF400). ${ }^{117}$ for preparing three different carbon-coated $\mathrm{V}_{2} \mathrm{O}_{5}$ composites. In the voltage window of 2.1-4.0 V, VCA11 had a discharge capacity of $292 \mathrm{~mA} \mathrm{~h} \mathrm{~g}^{-1}$ for the first cycle and a specific capacity of $261 \mathrm{~mA} \mathrm{~h} \mathrm{~g}^{-1}$ in the 30th cycle, with a fading rate of $0.36 \%$ per cycle. Cheah et al. ${ }^{119}$ developed a plasma-enhanced chemical vapour deposition (PECVD) method to synthesize carbon-coated $\mathrm{V}_{2} \mathrm{O}_{5}$ nanofibers. The carbon-coated VNFs exhibited better capacity retention characteristics than bare VNFs irrespective of the initial capacity values during prolonged cycling. Such an enhancement is mainly attributed to the homogeneous carbon coating by PECVD, which improves the electronic conducting profiles of VNF and prevents undesired side-reactions with electrolyte counterparts.

Ihsan et al. ${ }^{120}$ have recently developed an ultrasound assisted method followed by sintering to fabricate a $\mathrm{V}_{2} \mathrm{O}_{5} /$ mesoporous carbon composite. Mesoporous carbon, which has pore size between 2 and $50 \mathrm{~nm}$, facilitates electrolyte diffusion into the bulk of the electrode material and hence provides fast transport channels for the conductive ions. Obviously, amorphous structures of carbon and lattice fringes of $\mathrm{V}_{2} \mathrm{O}_{5}$ are observed. After sintering, the as-prepared $\mathrm{V}_{2} \mathrm{O}_{5} /$ mesoporous carbon showed good lithium storage properties with a high reversible capacity of $163 \mathrm{~mA} \mathrm{~h} \mathrm{~g}^{-1}$ after 100 cycles. The capacity retention of $\mathrm{V}_{2} \mathrm{O}_{5} / \mathrm{mc}$ was considerably higher than that of $\mathrm{V}_{2} \mathrm{O}_{5} \mathrm{np}$. Yu et al. ${ }^{121}$ rationally designed and synthesized $\mathrm{V}_{2} \mathrm{O}_{5}$ /ordered mesoporous carbon (CMK-3) composites via an ultrasonic method. The results showed that the ultrasonic synthesis method was flexible and efficient to highly disperse $\mathrm{V}_{2} \mathrm{O}_{5}$ nanoparticles in CMK-3. Zhang's group ${ }^{122}$ reported that carbon- 
coated $\mathrm{V}_{2} \mathrm{O}_{5}$ nanocrystals could be obtained via a unique capillary-induced filling strategy. The obtained nanocrystals exhibited markedly enhanced rate capability and excellent cyclability when used as the cathode material for Li-ion batteries. Guo et al. $^{\mathbf{1 2 3}}$ demonstrated that the electrochemical performance and stability of $\mathrm{V}_{2} \mathrm{O}_{5}$ nanowires could be significantly improved by coating a thin carbon layer as the shell. The $\mathrm{V}_{2} \mathrm{O}_{5}$ @C nanowires exhibited substantially enhanced capacitive performance compared to that of $\mathrm{V}_{2} \mathrm{O}_{5}$ nanowires.

\section{2 $\quad \mathrm{V}_{2} \mathrm{O}_{5}$ with carbon nanotubes}

Carbon nanotubes (CNTs) are allotropes of carbon with a cylindrical nanostructure. They find applications in LIB electrode materials owing to their extraordinary thermal, mechanical, and electrical properties. CNTs can be categorized as single-walled nanotubes (SWCNTs) and multi-walled nanotubes (MWCNTs). SWCNTs have high conductivity $\left(\approx 104 \mathrm{~S} \mathrm{~cm}^{-1}\right)$ and provide electronic conduction without blocking electrolyte access to the active material. MWCNTs show high mechanical and chemical stability, and the mesoporous character favors the diffusion of the reacting species. ${ }^{\mathbf{1 2 4 , 1 2 5}}$ CNTs are generally employed as conducting agents to replace carbon black when used in the electrode of LIBs. Nanocomposites containing $\mathrm{V}_{2} \mathrm{O}_{5}$ and CNTs are reported to have better lithium storage properties than bare $\mathrm{V}_{2} \mathrm{O}_{5}$ materials. This can be attributed to the flexible nature of the CNTs, which alleviate the internal stress caused during the charge-discharge process. With increased conductivity and surface area, such nanocomposites show enhanced lithium storage capability.

By early 2011, Seng et al. ${ }^{\mathbf{1 2 6}}$ prepared free-standing $\mathrm{V}_{2} \mathrm{O}_{5} /$ MWCNT films by a hydrothermal technique and filtration of ultra-long nanowires. The MWCNTs not only acted as conductivity modifiers, but also contributed to forming an integrated web-like structure. Yu's group ${ }^{127}$ proposed a facile hydrothermal approach to fabricate CNTs covered by interconnected $\mathrm{V}_{2} \mathrm{O}_{5}$ nanosheets, as illustrated in Fig. 13. After calcination in air, flakelike nanosheets of $\mathrm{V}_{2} \mathrm{O}_{5}$ could be observed, which were highly interconnected and covered the CNT skeleton. The interconnected $\mathrm{V}_{2} \mathrm{O}_{5}$-NSs were in intimate contact with the CNTs, which was favorable for the enhancement of conductivity. The as-derived CNTs@ $\mathrm{V}_{2} \mathrm{O}_{5}$ hybrid structure showed a larger reversible capacity over 100 cycles than the $\mathrm{V}_{2} \mathrm{O}_{5}$-mf sample. In the voltage window of 2.0-4.0 V, the CNTs@ $\mathrm{V}_{2} \mathrm{O}_{5}$ electrode delivered a capacity of 285 and $190 \mathrm{~mA} \mathrm{~h} \mathrm{~g}{ }^{-1}$ during the 1st and 100th cycle at the current rate of $1 \mathrm{C}$, respectively. Zhou and co-workers ${ }^{\mathbf{1 3 0}}$ used low-cost $\mathrm{V}_{2} \mathrm{O}_{5}$ powders and $\mathrm{H}_{2} \mathrm{O}_{2}$ as the raw materials to synthesize vanadium oxide nanosheet-MWCNT composite by a simple sol-gel method and

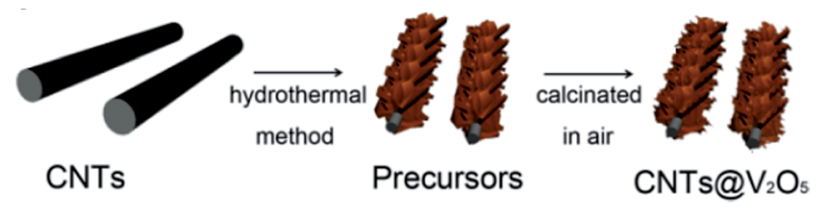

Fig. 13 Schematic of the synthesis process for CNTs@V $\mathrm{O}_{5} \cdot{ }^{127}$ hydrothermal process. It was found that $\mathrm{V}^{4+}$ was the predominant $\mathrm{V}$ element of the vanadium oxide nanosheet. The addition of carbon nanotubes improved the conductivity of the vanadium oxide nanosheets, exhibiting higher specific capacity and cycling stability than materials without carbon nanotubes. When the batteries were cycled between $1.5 \mathrm{~V}$ and $4 \mathrm{~V}$ at a constant current density of $50 \mathrm{~mA} \mathrm{~g}^{-1}$, the maximum discharge capacity of the vanadium oxide nanosheet-MWCNT composite was $238 \mathrm{~mA} \mathrm{~h} \mathrm{~g}^{-1}$ and $151 \mathrm{~mA} \mathrm{~h} \mathrm{~g}^{-1}$, respectively, after the 50th cycle. The good performance of the vanadium oxide nanosheet-MWCNT composite can be attributed to the sheet-like nanostructure having a large specific surface area and good structural flexibility, which can provide more $\mathrm{Li}^{+}$ion intercalation sites and accommodate large volume variations.

In contrast to the conventional strategy of coating the exterior and/or filling the interior of CNTs with $\mathrm{V}_{2} \mathrm{O}_{5}$, Chen et al. ${ }^{\mathbf{1 3 4}}$ proposed a novel strategy to fabricate MWCNT/ $/ \mathrm{V}_{2} \mathrm{O}_{5}$ core/shell nanostructures. They first used chemical vapor deposition (CVD) to grow an MWCNT sponge in a quartz tube at $860{ }^{\circ} \mathrm{C}$, which had very low density and high porosity. Then the sponge was cut into the desired size and placed in a commercial ALD reactor, where 1000 cycles of $\mathrm{H}_{2} \mathrm{O}$-based ALD $\mathrm{V}_{2} \mathrm{O}_{5}$ was deposited on it. The as-derived $\mathrm{MWCNT} / \mathrm{V}_{2} \mathrm{O}_{5}$ core/shell nanostructures showed excellent electrochemical performance. Zhou's group ${ }^{\mathbf{1 3 7}}$ have developed a simple hydrothermal route and subsequent post-sintering to fabricate a novel MWCNTs$\mathrm{V}_{2} \mathrm{O}_{5}$ composite with nanosized architecture. During the hydrothermal reaction, protonated hexadecylamine acted as an intermediator. The unique porous nanoarchitecture of MWCNTs $-\mathrm{V}_{2} \mathrm{O}_{5}$ provided a large specific surface area and a good conductive network, which facilitated fast lithium ion diffusion and electron transfer. Additionally, the uniformly dispersed MWCNTs conducting network also behaved as an effective buffer that could relax the strain generated during charge-discharge cycles. The as-prepared sample exhibited an initial specific capacity of $402 \mathrm{~mA} \mathrm{~h}^{-1}$, and it could remain $222 \mathrm{~mA} \mathrm{~h} \mathrm{~g}^{-1}$ after 50 cycles.

\section{3 $\quad \mathrm{V}_{2} \mathrm{O}_{5}$ with graphene}

The use of graphene can also enhance the cycling rate and electrochemical property of $\mathrm{V}_{2} \mathrm{O}_{5}$. As an important $2 \mathrm{D}$ carbonaceous material, graphene has quickly become an important focus of material science. It has good flexibility, high surface area, and excellent thermal and chemical stability and electrical conductivity. Compared with other carbon materials like amorphous carbon, graphite, and other carbon nanomaterials, graphene nanosheets (GNSs) can provide a higher buffer property for the deformation of active anode materials due to their flexibility reaction path and high volume expansion area; graphene also exhibits a better dispersion in nanotubes and nanoparticles. ${ }^{\mathbf{1 3 9}}$

Recently, Chen et al. ${ }^{\mathbf{1 4 0}}$ successfully prepared reduced graphene oxide (rGO)-encapsulated $\mathrm{V}_{2} \mathrm{O}_{5}$ nanocomposites by coassembly between negatively charged GO and positively charged oxide nanorods (Fig. 14). The process was driven by the mutual electrostatic interactions of the two species and was 


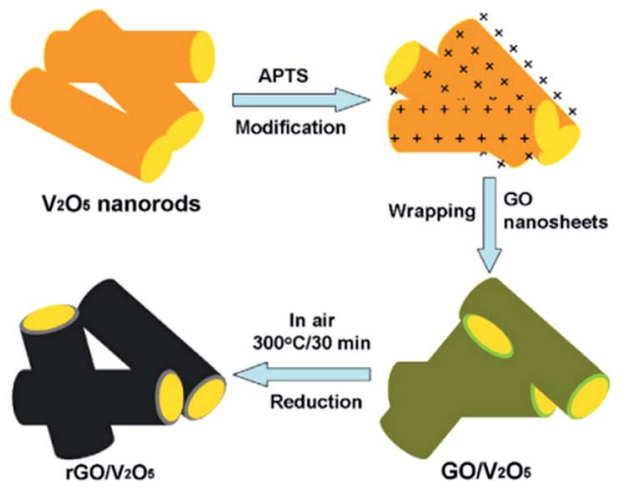

Fig. 14 Schematic of the fabrication of $\mathrm{rGO}$ enwrapped $\mathrm{V}_{2} \mathrm{O}_{5}$ nanorods. ${ }^{140}$

followed by thermal reduction. The as-synthesized nanocomposites possessed flexible and ultrathin rGO shells that effectively enwrapped the oxide nanorods. After several electrochemical tests, the nanocomposites presented excellent results. In the voltage window of 2.0-4.0 V, the cathode achieved an initial charge and discharge capacity of $287 \mathrm{~mA} \mathrm{~h} \mathrm{~g}^{-1}$ and $207 \mathrm{~mA} \mathrm{~h} \mathrm{~g}^{-1}$ during the first and 50th cycles at a current density of $100 \mathrm{~mA} \mathrm{~g}^{-1}$, respectively. Cheng's group ${ }^{\mathbf{1 4 1}}$ reported a simple solvothermal method to directly self-assemble $\mathrm{V}_{2} \mathrm{O}_{5}$ nanosheets on reduced graphene oxide (rGO). The $\mathrm{V}_{2} \mathrm{O}_{5}$ nanosheets/rGO hierarchical nanocomposites exhibited high reversible capacity and good rate capability compared to the bulk material by taking advantage of the synergetic effect of the two components.

Sun et al. ${ }^{\mathbf{1 4 3}}$ developed a hydrothermal method to fabricate hydrated vanadium pentoxide nanoribbons modified with reduced graphene oxide (rGO). The intertwining network structure provided efficient electron conduction pathways and short $\mathrm{Li}^{+}$diffusion distances. $\mathrm{Su}$ and co-workers ${ }^{\mathbf{1 4 7}}$ proposed a hydrothermal method to synthesize flexible $\mathrm{V}_{2} \mathrm{O}_{5}$ nanowires and then $\mathrm{V}_{2} \mathrm{O}_{5}$ /graphene composites were prepared via the dryfreezing step. It was found that the $\mathrm{V}_{2} \mathrm{O}_{5}$ nanowires were uniformly decorated on the surface of the graphene sheets. The unique nanocomposite expectedly exhibited an enhanced performance compared to pure $\mathrm{V}_{2} \mathrm{O}_{5}$ nanowires and $\mathrm{V}_{2} \mathrm{O}_{5}$ /graphene composites. Chen et al. ${ }^{\mathbf{1 4 8}}$ developed a facile solvothermal approach to synthesize the composite of $\mathrm{V}_{2} \mathrm{O}_{5}$ nanoparticles anchored on graphene. The as-prepared sample showed higher capacity and better cyclic capacity retention compared to bare $\mathrm{V}_{2} \mathrm{O}_{5}$, delivering a high reversible capacity of $153 \mathrm{~mA} \mathrm{~h} \mathrm{~g}^{-1}$ after 100 cycles.

\section{4. $\mathrm{V}_{2} \mathrm{O}_{5}$-Metal composites}

In order to overcome the shortcomings encountered in the application of $\mathrm{V}_{2} \mathrm{O}_{5}$ and improving its electrochemical performance, in addition to the above-mentioned nanocrystalline composites with different carbonaceous supports, cation doping has been an effective approach to improve lithium ion intercalation in $\mathrm{V}_{2} \mathrm{O}_{5}$, mainly because the introduction of alien ions into the $\mathrm{V}_{2} \mathrm{O}_{5}$ lattice may tune the ion occupation and the electronic structure of the host material. ${ }^{\mathbf{1 4 9}}$ Recently, utilization of metal nanoparticles to improve the electrical conductivity has attracted extensive attention. Crystal structure stability is important for the $\mathrm{V}_{2} \mathrm{O}_{5}$ cathode, which can be stabilized by doping of metallic elements such as $\mathrm{Al},{ }^{150,151} \mathrm{Cu},{ }^{152,158,163} \mathrm{Fe}^{153}$ $\mathrm{Cr},{ }^{154} \mathrm{Mn},{ }^{155,156,159} \mathrm{Sn},{ }^{157,164} \mathrm{Ag},{ }^{161} \mathrm{Mo},{ }^{160}$ and Ni. ${ }^{162}$ Table 5 summarizes the electrochemical properties of the cation doped $\mathrm{V}_{2} \mathrm{O}_{5}$ samples.

Wei et al. ${ }^{152}$ proposed a precipitation method followed by heat treatment to synthesize crystalline Cu-doped $\mathrm{V}_{2} \mathrm{O}_{5}$. $\mathrm{Cu}_{0.04} \mathrm{~V}_{2} \mathrm{O}_{5}$ showed better electrochemical performance than $\mathrm{V}_{2} \mathrm{O}_{5}$ because of its high electronic conductivity and good structural stability. Li and co-workers ${ }^{\mathbf{1 5 3}}$ employed electrostatic spray deposition technique to synthesize 3D porous $\mathrm{Fe}_{0.1} \mathrm{~V}_{2} \mathrm{O}_{5.15}$ thin films. The thin films were composed of rather porous spheres with diameters around 8 and $10 \mu \mathrm{m}$ for the Fe-doped samples. In the voltage window of 2.0-4.0 V, the cathode obtained an initial charge and discharge capacity of $255 \mathrm{~mA} \mathrm{~h} \mathrm{~g}^{-1}$ and $195 \mathrm{~mA} \mathrm{~h} \mathrm{~g}^{-1}$ during the first and 48th cycles at a current

Table 5 Electrochemical performance of cation-doped $\mathrm{V}_{2} \mathrm{O}_{5}$ samples for Li-ion battery cathode materials

\begin{tabular}{|c|c|c|c|c|c|}
\hline Precursor material & $\begin{array}{l}\text { Doped } \\
\text { metal }\end{array}$ & $\begin{array}{l}\text { Initial } \\
\text { capacity/mA h g }\end{array}$ & $\begin{array}{l}\text { Current } \\
\text { density/mA g }\end{array}$ & $\begin{array}{l}\text { Cycles }(\mathrm{N}) / \text { capacity } \\
\left(\mathrm{mA} \mathrm{h} \mathrm{g}^{-1}\right)\end{array}$ & References \\
\hline Vanadyl acetylacetonate & $\mathrm{Al}$ & 250 & 35 & $50 / 157.5$ & 150 \\
\hline $\mathrm{V}_{2} \mathrm{O}_{5}$ powders & $\mathrm{Al}$ & 216 & 150 & $50 / 162$ & 151 \\
\hline $\mathrm{V}_{2} \mathrm{O}_{5}$ powders & $\mathrm{Cu}$ & 229 & 100 & $60 / 160$ & 152 \\
\hline $\mathrm{NH}_{4} \mathrm{VO}_{3}$ & $\mathrm{Fe}$ & 255 & 58.8 & $48 / 195$ & 153 \\
\hline $\mathrm{V}_{2} \mathrm{O}_{5}$ powders & $\mathrm{Cr}$ & About 272 & 29 & $50 / 200$ & 154 \\
\hline $\mathrm{V}_{2} \mathrm{O}_{5}$ powders & $\mathrm{Mn}$ & 138 & 680 & $50 / 135$ & 155 \\
\hline Sodium metavanadate & Mn & 120 & 50 & 30/about 120 & 156 \\
\hline $\mathrm{NH}_{4} \mathrm{VO}_{3}$ & $\mathrm{Sn}$ & 251.1 & 200 & $50 / 212$ & 157 \\
\hline $\mathrm{NH}_{4} \mathrm{VO}_{3}$ & $\mathrm{Cu}$ & 196 & 300 & $70 / 186$ & 158 \\
\hline $\mathrm{VOSO}_{4} \cdot 3 \mathrm{H}_{2} \mathrm{O}$ & $\mathrm{Mn}$ & 251 & 300 & $50 / 201$ & 159 \\
\hline $\mathrm{V}_{2} \mathrm{O}_{5}$ powders & Mo & 203 & 44.1 & 50/about 92 & 160 \\
\hline $\mathrm{V}_{2} \mathrm{O}_{5}$ powders & $\mathrm{Ag}$ & 266.1 & 250 & $50 / 276.4$ & 161 \\
\hline $\mathrm{NH}_{4} \mathrm{VO}_{3}$ & $\mathrm{Ni}$ & 262 & 300 & $50 / 238$ & 162 \\
\hline $\mathrm{V}_{2} \mathrm{O}_{5}$ powders & $\mathrm{Cu}$ & 266 & 58.8 & $50 / 226$ & 163 \\
\hline $\mathrm{V}_{2} \mathrm{O}_{5}$ powders & $\mathrm{Sn}$ & 350 & 500 & $40 / 355$ & 164 \\
\hline
\end{tabular}


density of $58.8 \mathrm{~mA} \mathrm{~g}^{-1}$, respectively. We could ascribe the better cycling performance of the $\mathrm{Fe}_{0.1} \mathrm{~V}_{2} \mathrm{O}_{5.15}$ electrode to the improved stability of its layered structure. Li's group ${ }^{157}$ developed a microwave-assisted solvothermal synthesis to obtain a series of $\mathrm{Sn}$-doped $\mathrm{V}_{2} \mathrm{O}_{5}$ microspheres. The doping of $\mathrm{Sn}^{4+}$ also induced the formation of oxygen vacancies that would allow more active sites for the intercalation/extraction reactions of $\mathrm{Li}^{+}$. Therefore, the as-prepared sample showed excellent electrochemical properties. It could be attributed primarily to the lattice expansion upon doping that led to higher lithium diffusion coefficient than that of $\mathrm{V}_{2} \mathrm{O}_{5}$ as well as the presence of oxygen-rich vacancies.

Zou and co-workers ${ }^{158}$ developed a simple chemical reaction combined with ultrasonic mixing to synthesize nanostructured composites of $\mathrm{V}_{2} \mathrm{O}_{5}$ spheres decorated by electric Cu NPs. The decorated $\mathrm{Cu}$ NPs resulted in good contact with active materials and facilitated transportation of the electron into the inner region of the electrode. As expected, the $\mathrm{V}_{2} \mathrm{O}_{5} / \mathrm{Cu}$ cathodes could afford an obviously better electrochemical performance compared to pure $\mathrm{V}_{2} \mathrm{O}_{5}$, with a high reversible capacity of $186 \mathrm{~mA} \mathrm{~h} \mathrm{~g}^{-1}$ after 70 cycles under a current density of $300 \mathrm{~mA} \mathrm{~g}^{-1}$ and good rate performance. Zheng's group ${ }^{\mathbf{1 6 2}}$ developed a facile template-free nickel-mediated polyol process to prepare a high-performance $\mathrm{V}_{2} \mathrm{O}_{5}$ hollow microsphere for LIBs, in which nickel acted not only as the mediator to tailor the interior hollow structures of $\mathrm{V}_{2} \mathrm{O}_{5}$ and build a favorable 3D hierarchical nano-micron combined architecture, but also as doping units to tune vanadium valence states and improve lithium storage properties. Similarly, $\mathrm{V}_{2} \mathrm{O}_{5}$ doped with $\mathrm{Cu}^{2+}$ demonstrated excellent cycling stability and rate capability owing to its modified electronic conductivity and improved structural stability. ${ }^{163}$ Li et al. ${ }^{164}$ developed a sol-gel method to synthesize the homogeneous Sn-doped $\mathrm{V}_{2} \mathrm{O}_{5}$ sol. Preliminary three-electrode tests of the $\mathrm{Sn}$-doped $\mathrm{V}_{2} \mathrm{O}_{5}$ revealed good cycling performance. It was believed that $\mathrm{Sn}^{4+}$ would occupy the interstitial positions between $\mathrm{VO}_{5}$ slabs and form $\mathrm{SnO}_{6}$ octahedra with oxygen, leading to a slightly expanded lattice that facilitated $\mathrm{Li}^{+}$intercalation/extraction.

\section{Conclusion and outlook}

We attempt to provide a comprehensive review about $\mathrm{V}_{2} \mathrm{O}_{5}$-based nanomaterials as cathode materials for lithium-ion batteries. Starting with phase-pure $\mathrm{V}_{2} \mathrm{O}_{5}$, we have covered a wide range of nanostructures, from $1 \mathrm{D}$ nanorods/nanowires/nanotubes/ nanofibers/nanobelts to 2D nanosheets and 3D hollow and porous structures. For each category, we have discussed about the synthesis and lithium storage properties. For the 1D nanostructured materials, the most common synthesis methods are the hydrothermal method and sol-gel method. Hence, their preparation process is simple and feasible, and the requirements of the experimental conditions are not too high. For $2 \mathrm{D}_{2} \mathrm{O}_{5}$ nanosheets, the most common synthesis method is the hydrothermal method. Template-free and template-based methods are the main approaches for the synthesis of $\mathrm{V}_{2} \mathrm{O}_{5}$ hollow and porous structures. However, all three categories of $\mathrm{V}_{2} \mathrm{O}_{5}$ nanomaterials demonstrate significantly better electrochemical properties than bare $\mathrm{V}_{2} \mathrm{O}_{5}$ nanoparticles. These can be attributed to the following aspects. First, the nanostructures promote sufficient contact between the electrolyte and active materials. Hence, the nanostructures facilitate rapid electron transfer and mostly avoid the generation of high contact resistance, like a nanoparticle aggregated structure, thus ensuring satisfactory capacity retention even at high current densities. Finally, the existence of pyrolysed carbon improves the conductivity of the one-dimensional nanostructures.

Nanocomposites consisting of $\mathrm{V}_{2} \mathrm{O}_{5}$ and different carbonaceous supports have also been surveyed. Amorphous carbon, graphene, and carbon nanotubes are widely used as supports for electroactive $\mathrm{V}_{2} \mathrm{O}_{5}$. In such systems, $\mathrm{V}_{2} \mathrm{O}_{5}$ is usually decorated on graphene and CNTs, while amorphous carbon is hydrothermally coated on pre-synthesized $\mathrm{V}_{2} \mathrm{O}_{5}$ nanostructures. As potential cathode materials for LIBs, the $\mathrm{V}_{2} \mathrm{O}_{5}$ and different carbonaceous composites exhibit highly reversible capacities and better cycling performance. This excellent electrochemical performance is ascribed to their unique structures, which improve electrolyte infiltration and facilitate Li ion diffusion in the electrode. In addition, cation doping of lithium-ion battery (LIBs) cathode materials is beneficial to both ion diffusion and charge transfer in the electrochemical intercalation processes and hence may improve battery rate capability. As the cathode material for lithium-ion batteries, the cation-doped $\mathrm{V}_{2} \mathrm{O}_{5}$ samples exhibit better electrochemical performance compared than undoped ones.

By synthesizing $\mathrm{V}_{2} \mathrm{O}_{5}$ nanomaterials of various structures, low electrical conduction, slow $\mathrm{Li}^{+}$diffusion and irreversible phase transitions upon deep discharge can be alleviated to a certain extent. The cycling performance can be further improved effectively via creating unique nanocomposites. The significant progress achieved in the past decade re-assures the promising use of $\mathrm{V}_{2} \mathrm{O}_{5}$ as the cathode material in highperformance lithium-ion batteries. It is reasonable to confirm that $\mathrm{V}_{2} \mathrm{O}_{5}$-based nanocomposites with good electrochemical properties will find wide use in high-performance electrochemical energy storage devices in the near future. Nonetheless, it will still take a long time before metal oxide-based positive electrodes can be incorporated into commercial lithium-ion batteries. While the fundamental electrochemical processes are well understood for $\mathrm{V}_{2} \mathrm{O}_{5}$-based materials, the breakthrough will likely come from the delicate design and synthesis of nanocomposite electrode materials. Future research needs to deeply understand the structural evolution during cycling, possibly through in situ observation techniques and elaborate analysis of their atomic structure.

\section{Conflicts of interest}

There are no conflicts to declare.

\section{Acknowledgements}

This research was supported by a grant from the National Natural Science Foundation of China (No. 61504080 and No. 51676130). 


\section{References}

1 N. S. Choi, Z. H. Chen, S. A. Freunberger, X. L. Ji, Y.-K. Sun, K. Amine, G. Yushin, L. F. Nazar, J. Cho and P. G. Bruce, Angew. Chem., Int. Ed., 2012, 51, 9994-10024.

2 X. Y. Lai, J. E. Halperta and D. Wang, Energy Environ. Sci., 2012, 5, 5604-5618.

3 V. Mathew, S. Kim, J. Kang, J. Gim, J. Song, J. Baboo, W. Park, D. Ahn, J. Han, L. Gu, Y. Wang, Y. Hu, Y. Sun and J. Kim, NPG Asia Mater., 2014, 6, 138-147.

4 J. M. Tarascon and M. Armand, Nature, 2001, 414, 359-367. 5 M. Armand and J. M. Tarascon, Nature, 2008, 451, 652-657. 6 P. Simon and Y. Gogotsi, Nat. Mater., 2008, 7, 845-854.

7 R. Marom, S. F. Amalraj, N. Leifer, D. Jacob and D. Aurbach, J. Mater. Chem., 2011, 21, 9938-9954.

8 G. Girishkumar, B. McCloskey, A. C. Luntz, S. Swanson and W. Wilcke, J. Phys. Chem. Lett., 2010, 1, 2193-2203.

9 B. Scrosati and J. Garche, J. Power Sources, 2010, 195, 2419-2430.

10 F. Cheng, J. Liang, Z. Tao and J. Chen, Adv. Mater., 2011, 23, 1695-1715.

11 B. Xu, D. Qian, Z. Wang and Y. S. Meng, Mater. Sci. Eng., R, 2012, 73, 51-65.

12 J. Li, J. Klee Barillas, C. Guenther and M. A. Danzer, J. Power Sources, 2013, 230, 244-250.

13 M. M. Thackeray, C. Wolverton and E. D. Isaacs, Energy Environ. Sci., 2012, 5, 7854-7863.

14 A. P. Tang, X. Y. Wang, G. R. Xu, Z. H. Zhou and H. D. Nie, Mater. Lett., 2009, 63, 1439-1441.

15 J. Cabana, L. Monconduit, D. Larcher and M. R. Palacin, Adv. Mater., 2010, 22, 170-192.

16 A. S. Aricò, P. Bruce, B. Scrosati, J. M. Tarascon and S. W. Van, Nat. Mater., 2005, 4, 366-377.

17 H. Li, Z. X. Wang, L. Q. Chen and X. J. Huang, Adv. Mater., 2009, 21, 4593-4607.

18 X. F. Zhang, H. H. Zheng, V. Battaglia and R. L. Axelbaum, J. Power Sources, 2011, 196, 3640-3645.

19 Y. Wang, Y. Wang, E. Hosono, K. Wang and H. Zhou, Angew. Chem., Int. Ed., 2008, 47, 7461-7465.

20 L. Mai, Y. Dong, L. Xu and C. Han, Nano Lett., 2010, 10, 4273-4278.

21 B. Scrosati, J. Hassoun and Y. K. Sun, Energy Environ. Sci., 2011, 4, 3287-3295.

22 N. Alias and A. A. Mohamad, J. Power Sources, 2015, 274, 237-251.

23 Y. X. Wang, B. Liu, Q. Y. Li, S. Cartmell, S. Ferrara, Z. D. Deng and J. Xiao, J. Power Sources, 2015, 286, 330-345.

24 W. Waag, C. Fleischer and D. U. Sauer, J. Power Sources, 2014, 258, 321-339.

25 S. Goriparti, E. Miele, F. D. Angelis, E. D. Fabrizio, R. P. Zaccaria and C. Capiglia, J. Power Sources, 2014, 257, 421-443.

26 M. Okubo, E. J. Hosono, J. Kim, M. Enomoto, N. Kojima, T. Kudo, H. S. Zhou and I. Honma, J. Am. Chem. Soc., 2007, 129, 7444-7452.

27 K. S. Tan, M. V. Reddy, G. V. Subba Rao and B. V. R. Chowdari, J. Power Sources, 2005, 147, 241-248.
28 X. Xiong, D. Ding, Y. Bu, Z. Wang, B. Huang, H. Guo and X. Li, J. Mater. Chem. A, 2014, 2, 11691-11696.

29 X. Xiong, Z. Wang, G. Yan, H. Guo and X. Li, J. Power Sources, 2014, 245, 183-193.

30 R. Saroha, A. Gupta and A. Panwar, J. Alloys Compd., 2017, 696, 580-589.

31 Q. Liu, D. Mao, C. Chang and F. Huang, J. Power Sources, 2007, 173, 538-544.

32 C. W. Sun, S. Rajasekhara, J. B. Goodenough and F. Zhou, J. Am. Chem. Soc., 2011, 133, 2132-2135.

33 V. H. Nguyen, E. M. Jin and H. B. Gu, J. Power Sources, 2013, 244, 586-591.

34 J. M. Tarascon and M. Armand, Nature, 2001, 414, 359-367.

35 B. Kang and G. Ceder, Nature, 2009, 458, 190-193.

36 R. Baddour-Hadjean, C. Navone and J. P. Pereira-Ramos, Electrochim. Acta, 2009, 54, 6674-6679.

37 N. A. Chernova, M. Roppolo, A. C. Dillon and M. S. Whittingham, J. Mater. Chem., 2009, 19, 2526-2552.

38 D. McNulty, D. N. Buckley and C. O'Dwyer, J. Power Sources, 2014, 267, 831-873.

39 J. Mendialdua, R. Casanova and Y. Barbaux, J. Electron Spectrosc. Relat. Phenom., 1995, 71, 249-261.

40 C. Delmas, H. Cognac-Auradou, J. Cocciantelli, M. Menetrier and J. Doumerc, Solid State Ionics, 1994, 69, 257-264.

41 L. Q. Ma, J. Mater. Res., 2011, 26, 2175-2185.

42 C. Z. Wu and Y. Xie, Energy Environ. Sci., 2010, 3, 1191-1206.

43 H. L. Fei, H. J. Zhou, J. G. Wang, P. C. Sun, D. T. Ding and T. H. Chen, Solid State Sci., 2008, 10, 1276-1284.

44 A. D. Raj, T. Pazhanivel, P. S. Kumar, D. Mangalaraj, D. Nataraj and N. Ponpandian, Curr. Appl. Phys., 2010, 10, 531-537.

45 W. Zeng, W. G. Chen, Z. Y. Li, H. Zhang and T. M. Li, Mater. Res. Bull., 2015, 65, 157-162.

46 M. Kovendhan, D. P. Joseph, P. Manimuthu, A. Sendilkumar, S. N. Karthick, S. Sambasivam, K. Vijayarangamuthu, H. J. Kim, B. C. Choi, K. Asokan, C. Venkateswara and R. Mohan, Curr. Appl. Phys., 2015, 15, 622-631.

47 A. J. Waldir, C. Ribeiro, E. R. Leite and V. R. Mastelaro, Cryst. Growth Des., 2009, 9, 3626-3631.

48 T. Y. Zhai, H. M. Liu, H. Q. Li and D. Golberg, Adv. Mater., 2010, 22, 2547-2552.

49 L. J. Mao, C. Y. Liu and J. Li, J. Mater. Chem., 2008, 18, 16401643.

50 J. Liu, Y. C. Zhou, J. B. Wang, Y. Pan and D. Xue, Chem. Commun., 2011, 47, 10380-10382.

51 G. M. Zhu, Z. B. Qu, G. L. Zhuang, Q. Xie, Q. Q. Meng and J. G. Wang, J. Phys. Chem. C, 2011, 115, 14806-14811.

52 Y. Wang, H. J. Zhang, W. X. Lim, J. Y. Lin and C. C. Wong, J. Mater. Chem., 2011, 133, 2362.

53 A. M. Glushenkov, V. I. Stukachev, M. F. Hassan, G. G. Kuvshinov, H. K. Liu and Y. Chen, Cryst. Growth Des., 2008, 8, 3661-3665.

54 C. Zhu, J. Shu, X. Wu, P. Li and X. Li, J. Electroanal. Chem., 2015, 759, 184-189.

55 C. Peng, F. Xiao, J. Yang, Z. H. Li, G. T. Lei, Q. Z. Xiao, Y. H. Ding and Z. L. Hu, Electrochim. Acta, 2016, 192, 216-226. 
56 A. M. Glushenkov, M. F. Hassan, V. I. Stukachev, Z. P. Guo, H. K. Liu, G. Kuvshinov and Y. I. Chen, J. Solid State Electrochem., 2010, 14, 1841-1846.

57 K. Takahashi, S. J. Limmer, Y. Wang and G. Z. Cao, J. Phys. Chem. B, 2004, 108, 9795-9800.

58 Q. Shi, J. W. Liu, R. Z. Hu, M. Q. Zeng, M. J. Dai and M. Zhu, RSC Adv., 2012, 2, 7273-7278.

59 V. S. R. Channu, R. Holze and B. Rambabu, Curr. Appl. Phys., 2013, 13, 237-240.

60 S. SarKar, H. Banda and S. Mitra, Electrochim. Acta, 2013, 99, 242-252.

61 P. Yang and C. M. Lieber, Science, 1996, 273, 1836-1840.

62 D. K. Kim, P. Muralidharan, H. W. Lee, R. Ruffo, Y. Yang, C. K. Chan, H. L. Peng, R. A. Huggins and Y. Cui, Nano Lett., 2008, 8, 3948-3952.

63 H. W. Lee, P. Muralidharan, R. Ruffo, C. M. Mari, Y. Cui and D. K. Kim, Nano Lett., 2010, 10, 3852-3856.

64 E. Hosono, H. Matsuda, T. Saito, T. Kudo, M. Ichihara, I. Honma and H. S. Zhou, J. Power Sources, 2010, 195, 7098-7101.

65 L. Q. Mai, L. Xu, C. H. Han, X. Xu, Y. Z. Luo, S. Y. Zhao and Y. L. Zhao, Nano Lett., 2010, 10, 4750-4755.

66 J. M. Velazquez and S. Banerjee, Small, 2009, 5, 1025-1029.

67 M. C. Wu and C. S. Lee, J. Solid State Electrochem., 2009, 182, 2285-2289.

68 T. Y. Zhai, H. M. Liu, H. Q. Li, X. S. Fang, M. Y. Liao, L. Li, H. S. Zhou, Y. Koide, Y. Bando and D. Golberg, Adv. Mater., 2010, 22, 2547-2552.

69 A. K. Ramasami, M. V. Reddy, P. Nithyadharseni, B. V. R. Chowdari and G. R. Balakrishna, J. Alloys Compd., 2017, 695, 850-858.

70 Y. Tang, X. Rui, Y. Zhang, T. M. Lim, Z. Dong, H. H. Hng, X. Chen, Q. Yan and Z. Chen, J. Mater. Chem. A, 2013, 1, 82-88.

71 Y. Chen, G. Yang, Z. Zhang, X. Yang, W. Hou and J. J. Zhu, Nanoscale, 2010, 2, 2131-2138.

72 Y. Wang, K. Takahashi, H. M. Shang and G. Z. Cao, J. Phys. Chem. B, 2005, 109, 3085-3088.

73 C. J. Cui, G. M. Wu, J. Shen, B. Zhou, Z. H. Zhang, H. Y. Yang and S. F. She, Electrochim. Acta, 2010, 55, 2536-2541.

74 J. L. Sun, Mater. Lett., 2013, 108, 193-195.

75 R. Nadimicherla, Y. L. Liu, K. Q. Chen and W. Chen, Microelectron. Eng., 2014, 127, 81-85.

76 Z. T. Li, G. X. Liu, M. Guo, L. X. Ding, S. Q. Wang and H. H. Wang, Electrochim. Acta, 2015, 173, 131-138.

77 D. M. Yu, C. G. Chen, S. H. Xie, Y. Y. Liu, K. Park, X. Y. Zhou, Q. F. Zhang, J. Y. Li and G. Z. Cao, Energy Environ. Sci., 2011, 4, 858-861.

78 Y. L. Cheah, N. Gupta, S. S. Pramana, V. Aravindan, G. Wee and M. Srinivasan, J. Power Sources, 2011, 196, 6465-6472.

79 B. Yan, X. F. Li, Z. M. Bai, M. S. Li, L. Dong, D. B. Xiong and D. J. Li, J. Alloys Compd., 2015, 634, 50-57.

80 K. Dewangan, N. N. Sinha, P. G. Chavan, P. K. Sharma, A. C. Pandey, M. A. More, D. S. Joag, N. Munichandraiah and N. S. Gajbhiye, Nanoscale, 2012, 4, 645-651.

81 M. L. Qin, Q. Liang, A. Q. Pan, S. Q. Liang, Q. Zhang, Y. Tang and X. P. Tan, J. Power Sources, 2014, 268, 700-705.
82 C. L. Niu, J. B. Li, H. B. Jin, H. L. Shi, Y. Q. Zhi, W. Z. Wang and M. S. Cao, Electrochim. Acta, 2015, 182, 621-628.

83 P. P. Wang, Y. X. Yao, C. Y. Xu, L. Wang, W. He and L. Zhen, Ceram. Int., 2016, 42, 14595-14600.

84 X. H. Rui, Y. X. Tang, O. I. Malyi, A. Gusak, Y. Y. Zhang, Z. Q. Liu, H. T. Tan, C. Persson, X. D. Chen, Z. Chen and Q. Y. Yan, Nano Energy, 2016, 22, 583-593.

85 J. F. Huang, X. N. Qiao, Z. W. Xu, L. Y. Cao, H. Ouyang, J. Y. Li and R. Y. Wang, Electrochim. Acta, 2016, 191, 158-164.

86 X. Rui, Z. Lu, H. Yu, D. Yang, H. H. Hng, T. M. Lim and Q. Yan, Nanoscale, 2013, 5, 556-560.

87 Q. Y. An, Q. L. Wei, L. Q. Mai, J. Y. Fei, X. Xu, Y. L. Zhao, M. Y. Yan, P. F. Zhang and S. Z. Huang, Phys. Chem. Chem. Phys., 2013, 15, 16828-16833.

88 S. Q. Liang, M. L. Qin, Y. Tang, Q. Zhang, X. L. Li, X. P. Tan and A. Q. Pan, Met. Mater. Int., 2014, 20, 983-988.

89 H. Q. Song, C. P. Zhang, Y. G. Liu, C. F. Liu, X. H. Nan and G. Z. Cao, J. Power Sources, 2015, 294, 1-7.

90 Y. Xu, M. Dunwell, L. Fei, E. G. Fu, Q. L. Lin, B. Patterson, B. Yuan, S. G. Deng, P. Andersen, H. M. Luo and G. F. Zhou, ACS Appl. Mater. Interfaces, 2014, 6, 20408-20413.

91 S. Q. Liang, Y. Hu, Z. W. Nie, H. Huang, T. Chen, A. Q. Pan and G. Z. Cao, Nano Energy, 2015, 13, 58-66.

92 Y. W. Li, J. H. Yao, E. Uchaker, J. W. Yang, Y. X. Huang, M. Zhang and G. Z. Cao, Adv. Energy Mater., 2013, 3, 1171-1175.

93 A. Q. Pan, H. B. Wu, L. Zhang and X. W. Lou, Energy Environ. Sci., 2013, 6, 1476-1479.

94 H. Y. Wu, M. L. Qin, X. L. Li, Z. Q. Cao, B. R. Jia, Z. L. Zhang, D. Y. Zhang, X. H. Qu and A. A. Volinsky, Electrochim. Acta, 2016, 206, 301-306.

95 L. Q. Mai, Q. Y. An, Q. L. Wei, J. Y. Fei, P. F. Zhang, X. Xu, Y. L. Zhao, M. Y. Yan, W. Wen and L. Xu, Small, 2014, 10, 3032-3037.

96 X. Y. Zhang, J. G. Wang, H. Y. Liu, H. Z. Liu and B. Q. Wei, Materials, 2017, 10, 77-85.

97 E. Uchaker, N. Zhou, Y. W. Li and G. Z. Cao, J. Phys. Chem. C, 2013, 117, 1621-1626.

98 A. M. Cao, J. S. Hu, H. P. Liang and L. J. Wan, Angew. Chem., Int. Ed., 2005, 44, 4391-4395.

99 M. H. Chen, X. H. Xia, J. F. Yuan, J. H. Yin and Q. G. Chen, J. Power Sources, 2015, 288, 145-149.

100 C. Q. Feng, S. Y. Wang, R. Zeng, Z. P. Guo, K. Konstantinov and H. K. Liu, J. Power Sources, 2008, 184, 485-488.

101 H. E. Wang, D. S. Chen, Y. Cai, R. L. Zhang, J. M. Xu, Z. Deng, X. F. Zheng, Y. Li, I. Bello and B. L. Su, J. Colloid Interface Sci., 2014, 418, 74-80.

102 Q. Y. An, P. F. Zhang, F. Y. Xiong, Q. L. Wei, J. Z. Sheng, Q. Q. Wang and L. Q. Mai, Nano Res., 2015, 8, 481-490.

103 C. F. Zhang, Z. X. Chen, Z. P. Guo and X. W. Lou, Energy Environ. Sci., 2013, 6, 974-978.

104 Y. J. Dong, H. Y. Wei, W. Liu, Q. J. Liu, W. J. Zhang and Y. Z. Yang, J. Power Sources, 2015, 285, 538-542.

105 H. W. Bai, Z. Y. Liu, D. D. Sun and S. H. Chan, Energy, 2014, 76, 607-613.

106 A. Q. Pan, H. B. Wu, L. Yu, T. Zhu and X. W. Lou, ACS Appl. Mater. Interfaces, 2012, 4, 3874-3879. 
107 A. Q. Pan, H. B. Wu, L. Zhang and X. W. Lou, Energy Environ. Sci., 2013, 6, 1476-1479.

108 X. F. Zhang, M. Z. Wu, S. Gao, Y. M. Xu, X. L. Cheng, H. Zhao and L. H. Huo, Mater. Res. Bull., 2014, 60, 659-664.

109 L. Chen, X. Gu, X. L. Jiang, N. N. Wang, J. Yue, H. Y. Xu, J. Yang and Y. T. Qian, J. Power Sources, 2014, 272, 991-996.

110 J. Liu, Y. C. Zhou, J. B. Wang, Y. Pan and D. F. Xue, Chem. Commun., 2011, 47, 10380-10382.

111 Y. Ma, A. Huang, H. Zhou, S. Ji, S. Zhang, R. Li, H. Yao, X. Cao and P. Jin, J. Mater. Chem. A, 2017, 5, 6522-6531.

112 H. B. Wu, A. Q. Pan, H. H. Hng and X. W. Lou, Adv. Funct. Mater., 2013, 23, 5669-5674.

113 X. Liu, Y. J. Hu, G. Q. Jia, H. X. Zhang, H. Jiang and C. Z. Li, J. Mater. Chem. A, 2016, 4, 12030-12035.

114 A. Q. Pan, H. B. Wu, L. Yu and X. W. Lou, Angew. Chem., Int. Ed., 2013, 52, 2226-2230.

115 J. Y. Wang, H. J. Tang, L. J. Zhang, H. Ren, R. B. Yu, Q. Jin, J. Qi, D. Mao, M. Yang, Y. Wang, P. Liu, Y. Zhang, Y. R. Wen, L. Gu, G. H. Ma, Z. G. Su, Z. Y. Tang, H. J. Zhao and D. Wang, Nat. Energy, 2016, 1, 16050-16057.

116 A. Q. Pan, T. Zhu, H. B. Wu and X. W. Lou, Chem.-Eur. J., 2013, 19, 494-500.

117 J. Shin, H. Jung, Y. Kim and J. Kim, J. Alloys Compd., 2014, 589, 322-329.

118 J. Shin, T. Kim, J. Je, T. You and J. Kim, Electrochim. Acta, 2014, 139, 408-414.

119 Y. L. Cheah, R. V. Hagen, V. Aravindan, R. Fiz, S. Mathur and S. Madhavi, Nano Energy, 2013, 2, 57-64.

120 M. Ihsan, Q. Meng, L. Li, D. Li, H. Q. Wang, K. H. Seng, Z. X. Chen, S. J. Kennedy, Z. P. Guo and H. K. Liu, Electrochim. Acta, 2015, 173, 172-177.

121 L. Yu, C. X. Zhao, X. Long and W. Chen, Microporous Mesoporous Mater., 2009, 126, 58-64.

122 X. F. Zhang, K. X. Wang, X. Wei and J. S. Chen, Chem. Mater., 2011, 23, 5290-5292.

123 Y. Guo, J. Li, M. D. Chen and G. Z. Gao, J. Power Sources, 2015, 273, 804-809.

124 P. Zhou, X. Yang, L. He, Z. M. Hao, W. Luo, B. Xiong, X. Xu, C. J. Liu, M. Y. Yan and L. Q. Mai, Appl. Phys. Lett., 2015, 106, 113-116.

125 Z. L. An, L. He, M. Toda, G. Yamamoto, T. Hashida and T. Ono, Nanotechnology, 2015, 26, 195601-195608.

126 K. H. Seng, J. Liu, Z. P. Guo, Z. X. Chen, D. Z. Jia and H. K. Liu, Electrochem. Commun., 2011, 13, 383-386.

127 R. X. Yu, C. F. Zhang, Q. Meng, Z. X. Chen, H. K. Liu and Z. P. Guo, ACS Appl. Mater. Interfaces, 2013, 5, 12394-12399.

128 F. Carn, M. Morcrette, B. Desport and R. Backov, Solid State Sci., 2013, 17, 134-139.

129 W. Tang, X. G. Gao, Y. S. Zhu, Y. B. Yue, Y. Shi, Y. P. Wu and K. Zhu, J. Mater. Chem., 2012, 22, 20143-20145.

130 X. W. Zhou, G. M. Wu, G. H. Gao, C. J. Cui, H. Y. Yang, J. Shen and B. Zhou, Electrochim. Acta, 2012, 74, 32-38.

131 D. B. Kong, X. L. Li, Y. B. Zhang, X. Hai, B. Wang, X. Y. Qiu, Q. Song, Q. H. Yang and L. J. Zhi, Energy Environ. Sci., 2016, 9, 906-911.

132 Q. Guo, Z. H. Sun, M. Gao, Z. Tan, B. S. Zhang and D. S. Su, J. Energy Chem., 2013, 22, 347-355.
133 B. Sun, K. Huang, X. Qi, X. L. Wei and J. X. Zhong, Adv. Funct. Mater., 2015, 25, 5633-5639.

134 X. Y. Chen, H. L. Zhu, Y. C. Chen, Y. Y. Shang, A. Y. Cao, L. B. Hu and G. Rubloff, ACS Nano, 2012, 6, 7948-7955.

135 M. L. Qin, J. Liu, S. Q. Liang, Q. Zhang, X. L. Li, Y. Liu and M. Y. Lin, J. Solid State Electrochem., 2014, 18, 2841-2846.

136 Y. S. Hu, X. Liu, J. O. Muller, R. Schlogl, J. Maier and D. S. Su, Angew. Chem., Int. Ed., 2009, 48, 210-214.

137 X. W. Zhou, G. M. Wu, J. D. Wu, H. Y. Yang, J. C. Wang, G. H. Gao, R. Cai and Q. Y. Yan, J. Mater. Chem. A, 2013, 1, 15459-15468.

138 Z. Y. Cao and B. Q. Wei, Nano Energy, 2013, 2, 481-490.

139 J. Feng, C. Wang and Y. Qian, Mater. Lett., 2014, 122, 327-330. 140 D. Z. Chen, H. Y. Quan, S. L. Luo, X. B. Luo, F. Deng and H. L. Jiang, Phys. E, 2014, 56, 231-237.

141 J. L. Cheng, B. Wang, H. L. Xin, G. C. Yang, H. Q. Cai, N. Fude and H. Huang, J. Mater. Chem. A, 2013, 1, 1081410820.

142 Y. Yang, L. Li, H. L. Fei, Z. W. Peng, G. D. Ruan and J. M. Tour, ACS Appl. Mater. Interfaces, 2014, 6, 9590-9594.

143 Y. Sun, S. B. Yang, L. P. Lv, I. Lieberwirth, L. C. Zhang, C. X. Ding and C. H. Chen, J. Power Sources, 2013, 241, 168-172.

144 D. Pham-Cong, K. Ahn, S. W. Hong, S. Y. Jeong, J. H. Choi, C. H. Doh, J. S. Jin, E. D. Jeong and C. R. Cho, Curr. Appl. Phys., 2014, 14, 215-221.

145 V. S. R. Channu, D. Ravichandran, B. Rambabu and R. Holze, Appl. Surf. Sci., 2014, 305, 596-602.

146 H. B. Zhao, L. Y. Pan, S. Y. Xing, J. Luo and J. Q. Xu, J. Power Sources, 2013, 222, 21-31.

147 D. Z. Su, Y. J. Zhao, D. Yan, C. H. Ding, M. Q. Ning, J. S. Zhang, J. B. Li and H. B. Jin, J. Alloys Compd., 2017, 695, 2974-2980.

148 D. Chen, R. Yi, S. Chen, T. Xu, M. L. Gordin, D. P. Lv and D. H. Wang, J. Mater. Sci. Eng. B, 2014, 185, 7-12.

149 D. Vernardou, I. Marathianou, N. Katsarakis, E. Koudoumas, I. I. Kazadojev, S. O'Brien, M. E. Pemble and I. M. Povey, Electrochim. Acta, 2016, 196, 294-299.

150 Y. L. Cheah, V. Aravindan and S. Madhavi, ACS Appl. Mater. Interfaces, 2012, 4, 3270-3277.

151 K. Zhu, H. L. Qiu, Y. Q. Zhang, D. Zhang, G. Chen and Y. J. Wei, ChemSusChem, 2015, 8, 1017-1025.

152 Y. J. Wei, C. W. Ryu and K. B. Kim, J. Power Sources, 2007, 165, 386-392.

153 S. R. Li, S. Y. Ge, Y. Qiao, Y. M. Chen, X. Y. Feng, J. F. Zhu and C. H. Chen, Electrochim. Acta, 2012, 64, 81-86.

154 S. Y. Zhan, C. Z. Wang, K. Nikolowski, H. Ehrenberg, G. Chen and Y. J. Wei, Solid State Ionics, 2009, 180, 1198-1203.

155 D. M. Yu, S. T. Zhang, D. W. Liu, X. Y. Zhou, S. H. Xie, Q. F. Zhang, Y. Y. Liu and G. Z. Cao, J. Mater. Chem., 2010, 20, 10841-10846.

156 H. K. Park, Solid State Ionics, 2005, 176, 307-312.

157 Z. Y. Li, C. K. Zhang, C. F. Liu, H. Y. Fu, X. H. Nan, K. Wang, X. Y. Li, W. D. Ma, X. M. Lu and G. Z. Cao, Electrochim. Acta, 2016, 222, 1831-1838.

158 M. Z. Zou, W. W. Wen, J. X. Li, H. Lai and Z. G. Huang, J. Alloys Compd., 2016, 681, 268-274. 
159 H. M. Zeng, D. Y. Liu, Y. C. Zhang, K. A. See, Y. S. Jun, G. Wu, J. A. Gerbec, X. L. Ji and G. D. Stucky, Chem. Mater., 2015, 27, 7331-7336.

160 L. Q. Mai, W. Chen, Q. Xu, J. F. Peng and Q. Y. Zhu, Chem. Phys. Lett., 2003, 382, 307-312.

161 H. R. Peng, W. Z. Wu, C. Q. Zhang, G. C. Li and K. Z. Chen, Mater. Lett., 2011, 65, 3436-3439.
162 Y. Z. Zheng, H. Ding, E. Uchaker, X. Tao, J. F. Chen, Q. Zhang and G. Cao, J. Mater. Chem., 2015, 3, 1979-1985. 163 H. Yu, X. Rui, H. Tan, J. Chen, X. Huang, C. Xu, W. Liu, Y. W. Denis, H. H. Hng, H. E. Hoster and Q. Yan, Nanoscale, 2013, 5, 4937-4943.

164 Y. Li, J. Yao, E. Uchaker, M. Zhang, J. Tian, X. Liu and G. Cao, J. Phys. Chem. C, 2013, 117, 23507-23514. 